Andrews University

Digital Commons @ Andrews University

$10-2018$

\title{
Factors Contributing to 30-Day Readmission in Postsurgical Patients: A Reevaluation of Hospital Policies and Proposal for Change
}

Miriam Morgan-Skinner

Andrews University, morganskinn@andrews.edu

Follow this and additional works at: https://digitalcommons.andrews.edu/dnp

Part of the Nursing Commons

\section{Recommended Citation}

Morgan-Skinner, Miriam, "Factors Contributing to 30-Day Readmission in Postsurgical Patients: A Reevaluation of Hospital Policies and Proposal for Change" (2018). Doctor of Nursing Practice Projects.

2.

https://dx.doi.org/10.32597/dnp/2

https://digitalcommons.andrews.edu/dnp/2

This DNP Project is brought to you for free and open access by the Graduate Research at Digital Commons @ Andrews University. It has been accepted for inclusion in Doctor of Nursing Practice Projects by an authorized administrator of Digital Commons @ Andrews University. For more information, please contact repository@andrews.edu. 


\section{ABSTRACT}

\section{FACTORS CONTRIBUTING TO 30-DAY READMISSION IN POSTSURGICAL PATIENTS: A REEVALUATION \\ OF HOSPITAL POLICIES AND PROPOSAL FOR CHANGE}

by

\section{Miriam Morgan-Skinner}

Chair: Jochebed Bea Ade-Oshifogun 


\title{
ABSTRACT OF GRADUATE STUDENT RESEARCH
}

\author{
Scholarly Project \\ Andrews University \\ School of Health Professions
}

\section{Title: FACTORS CONTRIBUTING TO 30-DAY READMISSION IN POSTSURGICAL PATIENTS: A REEVALUATION OF HOSPITAL POLICIES AND PROPOSAL FOR CHANGE}

Name of researcher: Miriam Morgan-Skinner

Name and degree of faculty chair: Jochebed Bea Ade-Oshifogun, Ph.D., RN-BC, CNE

Date Completed: October 2018

\section{Background}

Readmission can cause much frustration for patients and families. The Center for Medicare and Medicaid Services (CMS) has emphasized the importance of finding ways to decrease readmissions within 30 days of discharge. In the southwest healthcare organization studied, the 30-day readmission rate for abdominal surgeries was $10 \%$. The goal of the study was to identify the causative factors for the readmissions and make appropriate suggestive changes. This project identified the factors contributing to the 30 day readmission rate in selected abdominal surgeries between January 2016-July 2017 and developed a policy to address the predominant factor. 


\section{Method}

After receiving institutional review board approval, the project author conducted a retrospective charts review. From the electronic health record (EHR) database at a southwest healthcare hospital system. 299 charts were selected. Thirty charts met the inclusion criteria and were analyzed using descriptive statistics. The FADE Model for quality improvement implemented served as the basis for practice review and changes through policy.

\section{Results}

Among all the factors examined, infection diagnosis accounted for $43 \%$ of reviewed readmissions, followed by small bowel obstruction, which accounted for $10 \%$ of readmissions, and abdominal pain which accounted for $7 \%$. The lack of communication with the patient about their treatment and plan of care is the most suggested cause of infection noted by the focus group. The project author developed a policy to improve the plan of care for postsurgical patients using CDC Policy process. The FADE Model helps to prioritize the process of policy development, which will improve patient care by reducing infection rates in surgical patients.

\section{Conclusion}

Postsurgical infection was the main factor contributing to 30-day readmission and a change in policy that was developed by the project manager and subsequently instituted by stakeholders has the potential of decreasing the readmission rate in the southwest healthcare hospital system. 
Andrews University

School of Health Professions

\title{
FACTORS CONTRIBUTING TO 30-DAY READMISSION IN POSTSURGICAL PATIENTS: A REEVALUATION OF HOSPITAL POLICIES AND PROPOSAL FOR CHANGE
}

\author{
A Scholarly Project \\ Presented in Partial Fulfillment \\ of the Requirements for the Degree \\ Doctor of Nurse Practice
}

by

Miriam Morgan-Skinner

October 2018 
CCopyright by Miriam Morgan-Skinner 2018 All Rights Reserved 


\title{
FACTORS CONTRIBUTING TO 30-DAY READMISSION IN POSTSURGICAL PATIENTS: A REEVALUATION OF HOSPITAL POLICIES AND PROPOSAL \\ FOR CHANGE
}

\author{
A project \\ presented in partial fulfillment \\ of the requirements for the degree \\ Doctor of Nursing
}

by

Miriam Morgan-Skinner

APPROVAL BY THE COMMITTEE:

Chair: Jochebed Bea Ade-Oshifogun

Dean, School of Health Professions

Emmanuel Rudatsikira

Member: Cynthia Small

Member: Eileen Willits

Date approved 


\section{DEDICATION}

This capstone scholarly project is dedicated to my husband, Jerome and my girls Briauna and Olivia, who gave me immeasurable love and support, to my brother Troy whose encouragement was invaluable, to my committee (Drs. Ade-Oshifogun, Small, and Willits), who taught me to persevere and endure, and finally to God for the wisdom and strength he bestowed on me. 


\section{TABLE OF CONTENTS}

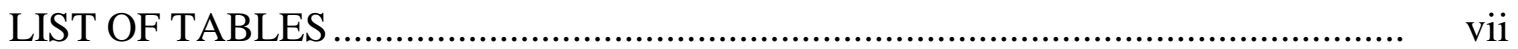

LIST OF FIGURES …….......................................................................... vii

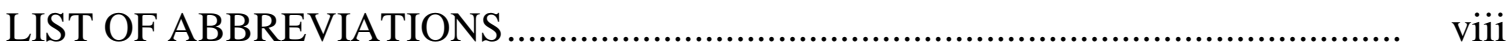

Chapter

1. OVERVIEW OF EVIDENCE-BASED PROJECT ......................................... 1

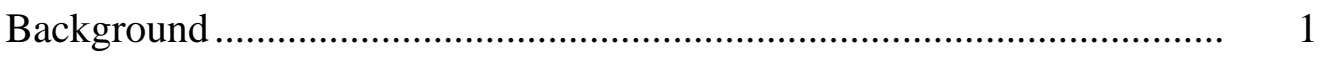

Purpose/Problem Statement .................................................................... 2

Significance and Implications................................................................... 3

Project Question...................................................................................... 4

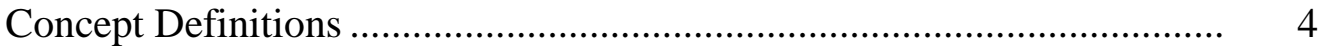

2. REVIEW OF SCHOLARLY EVIDENCE-BASED AND NARRATIVES .... 8

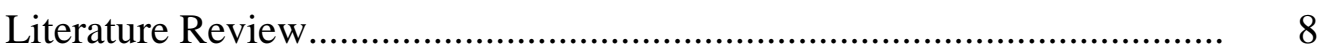

Literature Search Strategy.................................................................... 9

Background and Context..................................................................... 10

Factors Affecting Readmission........................................................... 11

Communication .......................................................................... 11

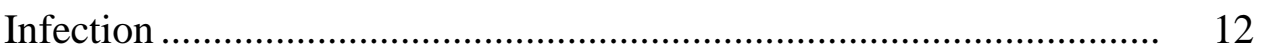

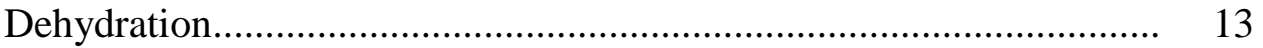

Obstruction or Adhesion ................................................................ 13

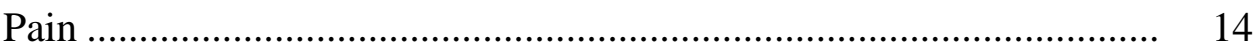

Health Literacy ............................................................................. 15

Policy Development .......................................................................... 16

Evaluation of Present Organization Policies for 30-day Readmission ....... 17

Overview of Theoretical Framework ....................................................... 18

Theoretical Foundation of the Project....................................................... 19

FADE Model............................................................................... 21

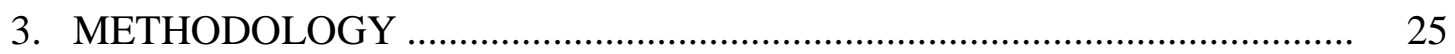

Approach and Rationale................................................................. 25 
Quantitative Method and Analysis..................................................... 27

Data Extraction Tool.............................................................................. 27

Qualitative Method and Analysis........................................................ 28

Sample Size ...................................................................................... 31

4. FINDINGS, DISCUSSION, IMPLICATIONS ........................................ 33

Results.................................................................................... 33

Quantitative Findings .................................................................. 33

Gender Distribution ............................................................... 33

Marital Status ........................................................................... 34

Length of Stay ................................................................... 35

Ages ................................................................................. 35

Average Number of Days Out Before Return................................. 36

Diagnosis Related Groups............................................................ 37

Infection ............................................................................ 39

Qualitative Findings ....................................................................... 40

Causes of Postsurgical Infection.................................................... 40

Poor Healthcare Staff Practices ................................................ 40

Patient Risk Factors ................................................................ 41

Patient Education ................................................................. 42

Patient Compliance ................................................................... 43

Skilled Nursing Facilities.......................................................... 44

Insurance ........................................................................... 45

Preventions of Postsurgical Infection ......................................... 45

Patient Education .................................................................... 46

Presurgery Planning Clinic Referral ......................................... 47

Healthcare Staff Education and Communication........................... 47

Discharge Planning ................................................................ 48

Proper Hygiene .................................................................... 49

Pain Management................................................................... 49

Better Staffing Ratio ............................................................... 49

Insurance ............................................................................. 50

Policy Development Process.......................................................... $\quad 50$

5. SCHOLARLY PROJECT FOR DISSEMINATION.................................. 54

Discussion of Project Results............................................................... 54

Focus Groups Brainstorming Themes from Qualitative Results ............. 56

Infection .......................................................................... 56

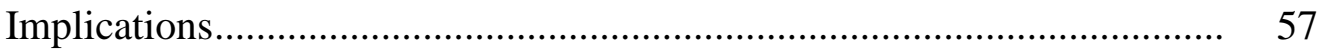

Impact on Policy ....................................................................... 57

Impact on Nursing Practice ......................................................... 58 
Project Strengths, Limitation, and Recommendation ............................ 59

Analysis of Self as a Professional .......................................................... 60

Analysis of Self as Scholar ................................................................... 60

Analysis of Self as Project Developer .................................................... 61

Meaning of Project for Future Professional Development ..................... 61

Impact on Practice................................................................................. 62

Plan for Dissemination of Project ...................................................... 62

Spiritual Component ........................................................................ 64

\section{APPENDIX}

A. INSTITUTIONAL LETTER OF AGREEMENT …..................................... 67

B. INSTITUTION IRB LETTER OF APPROVAL ........................................ 69

C. UNIVERSITY IRB LETTER OF APPROVAL .......................................... 71

D. UNIVERSITY IRB MODIFICATION APPLICATION ............................. 73

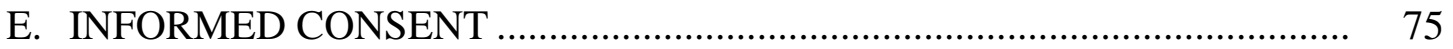

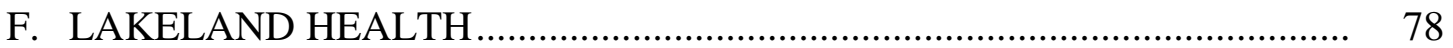

G. FOCUS GROUP INTERVIEW QUESTIONS ........................................ 83

H. DATA EXTRACTION TOOL ................................................................ 85

I. FISHBONE (ISHIKAWA) DIAGRAM ............................................... 90

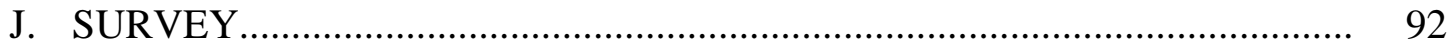

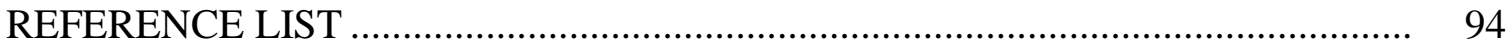




\section{LIST OF TABLES}

1. Causes of Readmission Percentage ..................................................... 39

2. Summary of Focus Group Discussion on Emerging Themes ........................ 40

3. Summary of Preventions Themes ........................................................ 46

4. Stakeholder Survey Result ................................................................... 52

\section{LISTS OF FIGURES}

1. The Johns Hopkins Nursing EBP Model .................................................. 19

2. Dorothy Orem's Theory Self-Care Deficit Applied to Project....................... 22

3. FADE Model of Quality Improvement Applied ....................................... 24

4. Gender Distribution Bar Chart ............................................................. 34

5. Marital Status Distribution Bar Chart ...................................................... 35

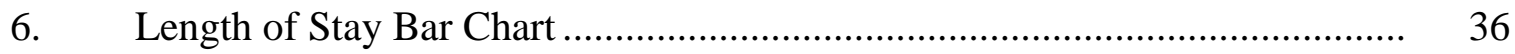

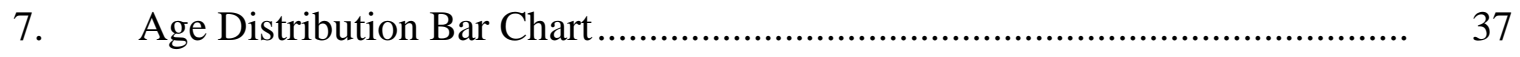

8. Number of Days Out Before Return Bar Chart ....................................... 38

9. Diagnosis Related Group Bar Chart ........................................................ 38 


\section{LIST OF ABBREVIATIONS}

ACA Affordable Care Act

AHRQ Agency for Healthcare Research and Quality

CDC Centers for Disease Control and Prevention

CMS Center for Medicare and Medicaid Services

DNP Doctor of Nursing Practice

DRG Diagnosis Related Group

DVT Deep Vein Thrombosis

EBM Evidence-Based Medicine

EBP Evidence-Based Practice

EHR Electronic Health Record

FADE Focus, Analyze, Develop, Evaluate

HF Heart Failure

HIPAA Health Insurance Portability and Accountability Act

IHI Institute of Healthcare Improvement

IRB Institutional Review Board

LOS Length of Stay

SNF Skilled Nursing Facilities 


\section{CHAPTER 1}

\section{OVERVIEW OF EVIDENCE-BASED PROJECT}

\section{Background}

There has been a growing focus on the impact of 30-day readmission for reimbursements to medical facilities by the governing healthcare bodies. The Affordable Care Act (ACA) included section 3025 to the Social Security Act. This established the readmission reduction program (Kassin et al., 2012). The program's initiative has been put into motion to prevent the Center for Medicare and Medicaid Services (CMS) from reimbursing facilities or reducing payments if there is an increased 30-day readmission rate. Healthcare agencies are encouraged to seek ways to reduce healthcare costs. Through the identification of modifiable variables, this study will propose a policy to help to reduce postabdominal surgery readmission within 30 days after discharge.

There are two reasons for this increased attention: the measure of the quality of care patients receive, and the potential variables that impact healthcare costs. Though all re-hospitalizations cannot be prevented, there are mitigating factors that can decrease the readmission percentile, beginning with improvements in the quality of care provided by the hospital. The CMS has emphasized the importance of finding ways to decrease readmissions within 30 days following discharge.

Evidence suggests that approximately $90 \%$ of readmissions are unplanned and cost Medicare over $\$ 17$ billion. This increased percentage and cost has led to increasing 
vigilance on the part of CMS. There is much interest regarding reimbursement from the CMS (CMS, 2017). The CMS readmission reduction program focuses on specific disease and requires institutions to adhere to certain process before they can be reimbursed. There are also financial penalties involved for providers who have too many readmissions (Lagoe, Nanno, \& Luziani, 2012). In 2009, CMS focused its efforts on educating hospitals that have readmissions within 30 days of discharge. Center for Medicaid and Medicare Services published data on specific disease processes that have increased 30day readmissions. These actions resulted in readmissions becoming the benchmark for quality patient care. Subsequently, the Patient Protection and ACA was created in 2010, and section 3025 held hospitals even more accountable for 30-day readmissions, reducing reimbursements if certain criteria were not met (Kassin et al., 2012).

\section{Purpose/Problem Statement}

In 2016, abdominal surgeries - namely, major small and large bowel procedures, minor small and large bowel procedures, and rectal resection - had an $8.63 \%$ readmission rate, a decrease of $2.68 \%$ since 2015. From January to July of 2017, there has been a $4.12 \%$ increase in readmissions at the southwest healthcare institution that is the focus of the proposed project. The purpose of the proposed scholarly project is to identify variables that contribute to increasing readmissions and to develop a healthcare policy that will assist in decreasing the rates of 30-day readmission for post-abdominal-surgery patients. Presently there is one policy at the institution in question that addresses the discharge and transition planning that does not affect 30-day readmission, but no policy addresses the processes to decrease infection and reduce the readmission rate for postabdominal-surgery patients. 
The institution's care management department created its discharge and transition planning policy. The policy addresses the need for an interdisciplinary approach that is initiated upon admission and continues throughout the patient's stay at the hospital. The policy is patient-centered and developed individually for each patient's social and clinical needs. The policy incorporates patient, family and significant others along with the multidisciplinary team in directing care (Huegel, 2014). However, there are gaps in the policy for decreasing postsurgical readmission. This project will attempt to fill those gaps for 30-day readmissions of post-abdominal-surgery patients.

\section{Significance and Implications}

The research is a quality improvement study that looks at possible areas of optimizing patient experience and reducing readmissions. Nurses and physicians play a paramount role in providing the best quality of life for patients across the spectrum of care. Discharge begins the day the patient makes the first contact with a healthcare provider. Nurses should work in collaboration with surgeons as well as internal medicine and family practitioners to commence the education process on admission. The policy developed will reflect recommendations for future practice through communication.

Due to this growth in readmission rates over the past decade, CMS has increased surveillance of healthcare organizations in order to to hold them more accountable. Recent governmental policy changes aim to reduce readmissions through payment incentives and care transition interventions because readmissions are pervasive, costly, and suggest poor quality care. Patient readmissions cost CMS 24 billion dollars and private pay insurance companies $\$ 8.1$ billion annually (Mittler et al.,2013). 
Abdominal surgeries have been the new focus of this southwest healthcare hospital system. This is due to the stagnation of the 30-day readmission rate for postabdominal-surgery patients in the last two years (L. Burton, personal communication, October 9, 2017). The project focused on this population because there is no evidence that a study was done at this organization. There was an opportunity to provide evidencebased research and contribute positively to the effort of improving patient satisfaction, decreasing 30-day readmission and increasing reimbursement.

\section{Project Question}

P - Post-abdominal-surgery patients at a southwest healthcare organization. These patients would have been admitted as an inpatient after surgery. These patients are between the ages of 18 and 90 years. The study will include both male and female patients.

I - The goal of the study is to identify potential causes for 30-day readmission. With this information, the project will be able to develop a policy to incorporate guidelines for reduction and prevention of 30-day readmissions of abdominal surgeries.

C - Continue current routine approach.

O - Policy creation aimed at reducing 30-day readmissions of abdominal surgeries.

The project question is: What are the causative factors for 30-day readmission and can policy development be used to incorporate guidelines to help with reduction and prevention of abdominal surgeries and rectal resection in a Southwest Healthcare Organization?

\section{Concept Definitions}

The following definitions are provided to promote comprehension: 
30-day readmission is defined as the readmissions within 30-days of initial discharge from an acute care hospital (CMS, 2018a). In this project, 30-day readmission will be calculated from the date of discharge to the date of return to the hospital for readmission following abdominal surgery. The list of readmissions included in this project was not exhaustive. Excluded were planned readmissions.

Policy creation is defined as a comprehensive method of identifying healthcare issues and then bringing those issues to healthcare Policy Committee (Zaccagnini \& White, 2014). In this project policy, creation includes facilitating brainstorming sessions with key stakeholders to identify causes for infection of abdominal postsurgical patients, then developing a policy to address the most frequently noted cause.

Abdominal wound infection postsurgery is defined as the introduction of human microorganisms from the exogenous environment and the endogenous organ microflora (Grice \& Segre, 2011). In this project, abdominal surgeries include Diagnosis Related Groups (DRG) 329 (major small and large procedures with major complications), 330 (major small and large bowel procedures with complications), 331 (major small and large bowel procedures without major complications), 333 (rectal resection with complications or comorbidities), and 334 (rectal resection without major complication or comorbidities).

Diagnosis Related Group is defined as a system that categorizes inpatient hospital visits severity of illness, the risk of mortality, prognosis, treatment difficulty, need for intervention and resource intensity. In this project, specific abdominal and rectal resection DRGs are used to identify the sample population (CMS, 2018b). 
Quality Improvement is defined as an organizational strategy that formally involves the analysis of process and outcomes data and the application of systematic efforts to improve performance (Agency for Healthcare Research and Quality [AHRQ], 2018). In this project, the Focus, Analyze, Develop, Evaluate (FADE) model is implemented.

Focus, Analyze, Develop, Evaluate model is defined as a form of quality improvement that is useful for focusing on a problem, analyzing the problem and its causes, developing and implementing a solution, and monitoring success (Alnaif, 2015).

Length of Stay (LOS) is defined as the duration of the hospital stay of a single admission. It is calculated by subtracting the day of admission from the day of discharge.

Number of Days Out Before Return is defined as the duration of a single abdominal postsurgical discharge before return for readmission. Number of days out before return is calculated by subtracting the day of discharge from the day of return.

Unplanned readmission is defined as emergent abdominal postsurgery and rectal resection hospitalization within 30-days after discharge.

Many types of insurances are accepted at the healthcare hospital system. However, the most significant percentage of patients are covered by Medicare. Since 2010, the CMS has shown increased interest in the outcome of each discharge and readmission within 30 days of initial discharge from an acute care hospital. Laws have been created to support this interest and healthcare organization such as the healthcare hospital system participating in this project need to identify and develop ways to minimize factors that may cause readmissions within 30-days (CMS, 2017). 
In summary, readmission rates are of interest to healthcare subsidiaries because of the extraordinary cost. The growing inquiry of readmissions has placed hospitals at the center of the prevention of readmission (Ma, McHugh, \& Aiken, 2015). Healthcare reform has pinpointed hospital readmissions as a key area for improving care coordination and achieving potential cost savings (AHRQ, 2014). 


\section{CHAPTER 2}

\section{REVIEW OF SCHOLARLY EVIDENCE-BASED}

\section{AND NARRATIVES}

\section{Literature Review}

The purpose of the evidence-based quality improvement project was to identify factors that cause 30-day readmission of postsurgical patients, reevaluate the hospital policies and propose a change of said policies by creating a policy to reflect the findings. The 30-day readmission metric has gained much attention from the CMS. Center for Medicaid and Medicare Services has a vested interest in the percentage of 30-day readmissions as it pertains to reimbursements to healthcare organizations (CMS, 2018a).

Center for Medicaid and Medicare Services believes that hospital readmission within 30 days of an initial hospitalization is receiving increased analysis as an indicator of sub-par quality patient care (Kassin et al., 2012). In 2010 section 3025 of the ACA required the establishment of a hospital readmission reduction program (HRRP). The HRRP commenced in 2012. The HRRP program lowers payments to inpatient hospitals with increased readmissions. The parameters set forth by HRRP for 30-day readmission include:

- Any unplanned readmissions within 30 days of discharge from initial admission.

- Patients readmitted to the same hospital or another acute care hospital for any reason. 
Readmissions to any acute care hospital are counted, no matter what the principal diagnosis was. However, if readmission was planned, then the measures set forth do not apply (CMS, 2018).

This chapter will discuss the following issues: (a) readmission as defined by CMS; (b) types of readmissions; (c) readmission in a surgical patient;(d) abdominal surgery readmissions; and (e) factors that cause readmissions. This chapter also includes the evidence-based model and the theoretical framework by Dorothy Orem which supports this project.

\section{Literature Search Strategy}

A comprehensive literature search was carried out to find evidence-based studies on 30-day readmission of postsurgical patients. The following databases were used: CINAHL, MEDLINE, ProQuest, EBSCO, Joanna Briggs Institute EBP Database, PubMed, Mayo Clinic, Google Scholar, Michigan annual review of public records, and Center for Disease Control health literacy for public health professions.

The following keywords were used: 30-day unplanned readmission, Post Abdominal Surgery, Quality of Care, Policy, Chart Review, factors that cause 30-day readmission, interventions, literacy, education. These searches revealed information about factors that cause 30-day readmission and emphasized the outline that supported the project.

The review covered current, informative, peer-reviewed literature from 2011 to 2018. The search produced 259 articles that included systematic reviews, descriptive statistics, meta-analysis, nursing dissertations, retrospective, qualitative, and quantitative analysis. Evidence level of the article was based on the study, randomization, size of the 
sample, and reduction of an article to those pertinent to the study. The evidence-based medicine $(\mathrm{EBM})$ model incorporates appropriate research findings with appropriate expertise. The value of the evidence is measured by its level. The higher the level, the more substantial and robust the study.

A final sample of 40 research articles was reviewed; criteria included an adult patient population aged 18 years and older with one of the following: major abdominal surgery with or without major complication or comorbidity, or minor abdominal surgery with or without major complication or comorbidity, or rectal surgery with or without major complication or comorbidity. Articles were excluded that addressed neurological, gynecological, vascular and cardiovascular surgeries. In this review, 14 studies are type 1a (systematic review), six studies are type $1 \mathrm{~b}$ (randomized control), five studies are II a (cohort studies), five studies are type III b (case-control studies), and ten studies are type V (expert opinion). The criteria used for this review was from (Essential Evidence Plus, 2018; Oxford Centre for EBM, 2011; University of Washington, 2018).

\section{Background and Context}

Readmission may be due to unresolved acute illness, continued chronic illness, gaps in care in the outpatient setting or development of new illnesses. Readmission is the benchmark of CMS and rates at the $80^{\text {th }}$ percentile or lower are considered ideal (Mayo Clinic, 2018). Readmission can be either planned or unplanned. Planned readmission is one that is scheduled with the physician or the provider prior to discharge. Unplanned readmission involves returning to the same or similar inpatient hospital without such scheduling. Unplanned readmission may or may not be preventable and is one indicator of clinical deterioration, which requires increased cost of care. Center for Medicaid and 
Medicare Services considers all unplanned readmissions unnecessary spending (Mayo Clinic, 2018; Ohnuma, Shinjo, Brookhart, \& Fushimi, 2018).

Readmission is a major concern for the healthcare industry. Inpatient hospitals and specifically their clinicians and policymakers must focus on the quality of care as well as cost containment. The expansion beyond medical conditions to include surgeries came with harsh punishments. It is incumbent on healthcare organizations to identify factors that may cause readmissions and decide on ways to tackle the problem.

For most of its effective period, section 3025 of the ACA has focused on six measures: acute myocardial infarction, heart failure, pneumonia, chronic obstructive pulmonary disease, coronary artery bypass graft surgeries, and elective primary total hip and/or total knee arthroplasty. Since the enactment of section 3025, there has been more focus on surgical procedures, and financial penalties for readmission have been expanded beyond medical conditions to include surgical procedures such as abdominal surgery.

\section{Factors Affecting Readmission}

Readmission is the return to an inpatient healthcare facility and being admitted for further treatment. Admission may be for many reasons. Factors that increase the frequency of readmission include poor communication between multidisciplinary team members, infection, LOS, dehydration, deep vein thrombosis (DVT), obstruction at the site or areas of surgery and preexisting acute or chronic disease process (Chen, 2013; Cheng et al., 2017; Hari \& Rosenzweig, 2012; Mittler et al., 2013; Morris et al., 2011).

\section{Communication}

Effective communication between disciplines is paramount in agreeing on the best plan of care for the patient. It is through a multidisciplinary approach that the healthcare 
team can connect the dots and provide adequate resources to provide the best care possible for a successful outcome. Evidence also suggests that well-organized multidisciplinary teams may increase patient satisfaction (Leach et al., 2017).

Chen (2013) suggested that miscommunication among the multidisciplinary team in areas such as discharge plans, discharge summaries, discharge instructions, and patient education has a correlation to increased readmissions. Sarin et al. (2016) also identified a strong correlation between effective interdisciplinary communication and LOS.

Specifically, Chen analyzed the communications between multidisciplinary teams and 82 patients at discharge. Chen found that having effective communication between disciplines and patient may reduce readmission.

\section{Infection}

Infection is one of the leading causes of readmissions. Surgical site infections are among the most frequent healthcare infections and represent a common complication for patients who undergo surgery (Napolitano, Tomassoni, Cascone, Di Giuseppe, \& The Collaborative Working Group, 2018). The skin, a natural barrier against infection, is broken, thus permitting bacteria to enter the wound. However, there are multiple reasons why patients may end up with an infection after surgery (John Hopkins Medicine, 2018).

The rate of postsurgical site infections ranges from one percent to approximately 50 percent, depending on the duration of the surgery (Cheng et al., 2017). Understanding these factors and identifying solutions is paramount in decreasing infection. Reinberg (2015) found that there are various factors that may lead to surgical site infection including the improper technique of healthcare providers as well as patient lifestyles and living conditions both preoperatively and postoperatively. 


\section{Dehydration}

Dehydration is noted as when the body output is more than its input of fluids. Among the populations most vulnerable to dehydration, geriatric patients have an unusually high rate of susceptibility. This is because advancement in age causes abnormal hemodynamics, such as a decrease in the sensation of thirst. Medications may also contribute to dehydration. (Jerónimo, Segura, \& Amorós, 2015). Provider vigilance is needed when prescribing and counseling medication administration before surgery for both patient and caregiver. Having a balanced diet with adequate nutrition and hydration is also essential before and after surgery.

Education on the side effects of medication is likewise imperative to help this population identify potential causes of and ways to prevent dehydration. Serra-Majem (2015) found that dehydration is the second most common factor for all hospitalizations. Proper monitoring during and after surgery is necessary to prevent dehydration.

\section{Obstruction or Adhesion}

Obstruction or adhesions of the surgery site can cause readmissions. Adhesions or obstructions may cause other complications such as ilius, or malnutrition, these are medical concerns and must be addressed with urgency. The cause of this process is unknown and can occur even after adequate interventions are taken (Aquina et al., 2016). However, obstructions and adhesions may be identified more quickly if patients are given access to postoperative office visits sooner after discharge.

Bowel obstruction may be due to the poor knowledge base of the patient or caregiver about what to look for and how to take care of the wound. Sutherland et al. (2016) in their study analyzed the reasons for readmission for 46 patients within 30 days 
post discharge. Sutherland et al. (2016) also found that in addition to dehydration, fever, and ileus (or small bowel obstruction) were the primary readmission diagnoses. As it relates to the diagnosis of obstructions or adhesions, two areas identified as possible causes and subsequent readmission within 30 - days postoperatively include (a) Late or delayed follow-up visits with the surgeon or a physician in the same practice and (b) The inability to care for themselves postoperatively.

\section{Pain}

Pain is another cause of readmission of the surgical patient within 30 days after discharge. Pain is subjective and cannot be quantified by the medical staff. Patients may respond to pain in different ways depending on various factors. These factors may include the patient's pain threshold, mental state, history of poor pain management, opioid addictions, existing diagnosis of chronic pain. Pain can prevent or delay the healing process and cause secondary diagnosis of pneumonia as well as DVT (Francis \& Fitzpatrick, 2013).

Chronic pain is a problem within the healthcare system. Postoperative chronic pain has many psychological, environmental and biological facets and can be complicated (Clarke et al., 2015). An increase in patient literacy leads to a better ability to manage pain levels. Therefore, it is imperative that part of the patient's communication with healthcare providers include thorough yet straightforward educational instructions that will provide them with more options to relieve pain including diversion therapy. Köppen, Dorner, Stein, Simon, and Crevenna (2018) analyzed the health literacy level and pain intensity for 121 patients. Köppen et al. (2018) found evidence that showed a 
strong correlation between chronic pain and health literacy and that patients with higher health literacy showed less pain intensity.

\section{Health Literacy}

The ability to navigate adequately through healthcare systems and make better health decision is lacking in 33 percent of the United States adult population (Hersh, Salzman, \& Snyderman, 2015). Statistically, 44 million adults are now unable to read a simple story to their children, $50 \%$ of adults cannot read a book written at an eighth-grade level, and 45 million are functionally illiterate and read below a 5th-grade level (Literacy Project Foundation, 2015).

Much of the US population lacks health literacy, which causes delays in healthcare process resulting in a deficiency in care. Education is paramount in reducing health literacy. Although US adults on average read at an eighth-grade level, more than $75 \%$ of patient education materials are written at a high school or college reading level (Hersh et al., 2015). Learning through education cannot occur if the information shared is too advanced for comprehension. It is important that information shared with the patient be written at an education level that is statistically proven to be reader-friendly.

Education is an important factor in preventing readmissions. Educating the patient on how to perform tasks before surgery and what to look for after surgery is important in decreasing readmissions as a result of wound infection. Such reductions are often seen following basic instructions by the healthcare providers. However, what seems simple to the healthcare provider may be an overwhelming task that requires direction and demonstrations for the patient. Dadosky et al. (2016) analyzed the effect of enhanced education on 228 patients. Dadosky et al. (2016) found that in addition to the information 
given in the admission process, introduction of small education sessions before discharge is effective in reducing 30-day readmissions.

\section{Policy Development}

An integral part of policy development is assessing the opinions of key stakeholders through focus groups. Focus groups are an effective method of learning more about the experiences, perceptions and emotions of the key stakeholders within the area of focus (Clemson University, 2018). In this project, surgery, specialty departments and clinics were the key stakeholders. In this quality improvement project, focus groups will produce data needed to develop a policy to facilitate continuous improvement in the reduction of infections that cause 30 -day readmissions.

The process of policy development has multiple facets. The process of conceptualizing, developing, adopting and evaluating is rarely a linear process; often the domains of the policy cycle overlap or occur out of order. However, in the ideal scenario, a problem is defined; potential policy solutions are identified, analyzed, and prioritized; and the best solution is adopted and evaluated (Centers for Disease Control and Prevention [CDC], 2018).

The subject organization has experienced a $\$ 1.1$ million deficit in surgeries alone either through delay in surgery or cancellation cases due to poor optimization (L. Burton, personal communication, October 9, 2017). There are several areas of focus within surgery. However, this project focused on one aspect of surgery-namely, readmission within 30 days of abdominal surgery and rectal resection. 


\section{Evaluation of Present Organization Policies for 30-day Readmission}

This project identified 30-day readmission rates of abdominal surgeries as a concern of the southwestern healthcare organization. The organization statistics showed an 8.63 percent readmission rate in 2016 and a 12.75 percent rate from January to July of 2017, representing an increase of 4.12 percent within six months (D. Wolf, personal communication, September 18, 2017).

While the organization was able to identify the increase in the percentage of readmission within 30 days of initial discharge, there were gaps in the data. There was a single resource that identified factors that may cause 30-day readmissions. There was no one process that guided the practices of healthcare providers. The Institutional Review Board (IRB) within the organization approved the process of this project.

A thorough search of the organization's policies and procedures showed no policy that deals directly with addressing factors of readmissions of abdominal postsurgical patients. Amongst the policies, there is one that deals with the process of interdisciplinary discharge approach but not specifically with education. Another policy deals with the clarity of patient information in presurgery optimization and one that dealt with interdisciplinary discharge approach. The seven presurgery clinic policies suggested referral of patients that needed further optimization. One policy looked briefly at the education of the patients. However, the education would be specific only to the patient population the clinic sees. The discharge policy was specific to the information and resource that care managers could provide to all patients upon discharge. There was no education policy that addresses all surgical patients through the spectrum of care, from 
initial visit with the doctor in the surgery office, intraoperative care, and after-surgery care.

Another policy reviewed deals with "evaluation and teaching topics" where the practitioner's key focus is to provide patients with education aimed at optimizing medical status and controlling comorbidities. The education is specific to areas such as mental health, physical activity, nutrition and pain management. There were no policies specific to educating preoperative and postoperative patients about how to care for themselves using language easy to understand. The remaining policies made no mention of educating patients on self-care. This gap poses an opportunity to develop a policy that not only enhances the education process of the patient but also improves patient outcome and increases reimbursement from CMS.

This project received valuable input from key stakeholders within the surgical specialty. Focus groups were created using key stakeholders to identify root causes that may contribute to the most common factors of 30-day readmission within the organization. The stakeholders are also important in that soliciting their input may result in their buy-in of the policy and its implementation.

The policy was drafted with significant consideration of the stakeholder's invaluable input. The drafted policy was sent to the organization's internal policy committee members for their feedback. This project shall follow all internal procedures needed to get the policy enacted or passed (CDC, 2018).

\section{Overview of Theoretical Framework}

Postoperative 30-day readmission rates have been researched in detail. This evidence-based practice (EBP) project will utilize existing studies to build on 
acknowledged evidence and highlight best practices in both outpatient and inpatient postoperative settings. This project will include an underpinning that incorporates Dorothea Orem's theory of self-care deficit, the EBM model (see Figure 1), and a wideranging literature search to build a platform for a practice change. This chapter will discuss these frameworks and how they promoted a practice change in this project. The review of the current evidence will be presented with an in-depth appraisal that builds the foundation for this practice change. The Problem, Intervention, Control, Outcome question was developed using these frameworks and evidence to start this process.

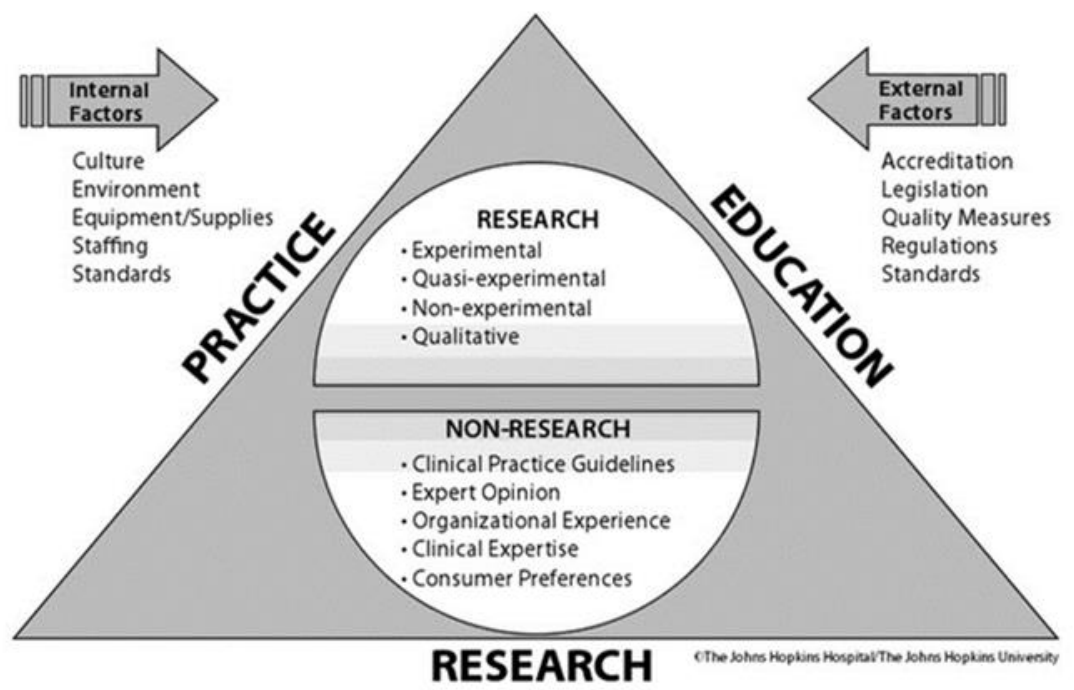

Figure 1. The Johns Hopkins Nursing EBP Model (Dearholt, Dang, \& Sigma Theta Tau International, 2012).

\section{Theoretical Foundation of the Project}

Orem's (1995) Self-Care Theory will guide this study to recognize the self-care requirements imposed on patients undergoing surgery or disease processes, whether 
chronic or acute. This theory assumes that human beings are involved in continuous communication, which allows them to share resources with each other and their environments to function and to preserve life. Individuals are assumed to understand when to act and make appropriate judgments about their needs. Orem's theory also notes that through maturity, human beings experience hardships in practicing self-care; therefore, agencies involved in their care are implored to assist in identifying outstanding needs and provide the means to improve others' self-care (Orem, 1995).

In part, nursing is a therapeutic measure for sustaining life and health. The provision of education about self-care, recuperating from illness or injury, or coping with their effects encompasses nursing. Orem's theory discusses three self-care components: theory of self-care, theory of self-care deficit, and theory of nursing system. The first addresses the needs that are common to all individuals. The second addresses those needs that result from personal maturation or development because of a particular condition or event. The third necessity is health deviation as a result of illness, injury, disease or treatment. This project focuses on surgical interventions as a result of acute or chronic illness, which fall into the third necessity.

Orem (1995) states that the nursing staff must provide patients and caregivers with the necessary tools to meet the third need. These tools may include adequate basic education about procedures and expectations, the provision of resources for additional assistance when discharged, adequate supplies for proper wound care and a simple explanation of the importance of a clean home environment. This is to prevent health deviation, stagnation or regression which may cause readmission within 30 days of initial discharge. 
The theory also encourages nurses (practitioners and physicians) to empower patients through education to create a helping system in situations where people are likely to have an existing or potential self-care deficit (Hari \& Rosenzweig, 2012). This includes timely follow-up appointments to monitor the progression of healing, as well as to provide additional care for suspected infection before it progresses, consistent discharge and verbal instructions, and resources that will benefit the patient and provide support for healing.

This project utilizes Orem's Theory to show the process needed to decrease the most significant cause of readmission within the surgical population studied. Below is the application of the process (Figure 2).

\section{FADE Model}

The FADE, or "focus, analyze, develop and execute" model of quality improvement is an ongoing effort to improve performance (Health Resource and Service Administration, 2011). Using the FADE model in this quality improvement project enabled the author to identify key steps in the policy development process.

This quality improvement project aims to create a policy that addresses the significant factor that causes 30-day readmission of post abdominal surgeries. This project includes phases of the FADE Model of quality improvement. In the first phase of this improvement project—Focus — readmission was identified as the main focus of withholding reimbursements through evidence-based research and mandates made by the Center for Medicaid and Medicare Services. This project focused on one subset of the problem, 30-day readmission of surgical patients. 


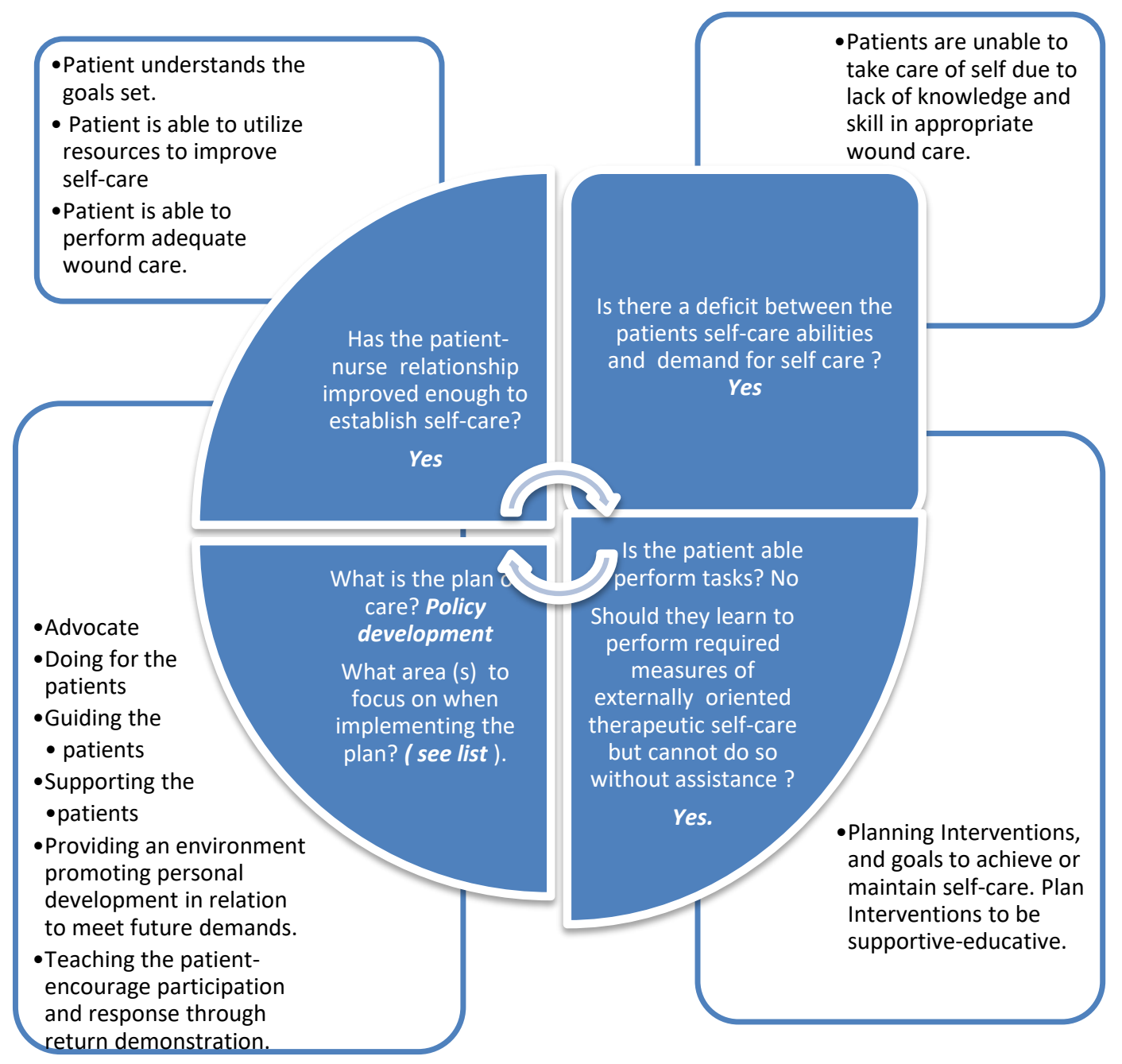

Figure 2. Dorothy Orem's Theory of Self-Care Deficit Applied to Project

In the analysis process, the second phase of this project, factors were identified that caused 30-day readmission of postsurgical patients. This was done by using the electronic health record (EHR) "Epic" to identify key components of this patient population and document them on the data extraction tool that was created specifically 
for this project. The process was done retrospectively using descriptive analysis (Duke University, 2018).

Talking with people who actively work in the system is a useful way to learn more about identifying solutions (Institute of Healthcare Improvement [IHI], 2018). In the development stage, members of the healthcare team engaged in various brainstorming sessions through focus groups to ascertain their opinions on what factors they believed caused 30-day readmissions. These sessions will not only allow different areas of the healthcare system to participate in finding a solution to decrease 30-day readmissions, but it will also positively affect their buy-in and future participation when the final policy is implemented.

The members of the healthcare team who chose to participate in the brainstorming sessions performed a root cause analysis of the common predictor of 30-day readmission of surgical patients. The fishbone analysis diagram (see Appendix I.), a tool used to guide the participants of this project, helps to analyze problems, identify potential causes and give every participant an insight into the problem so that collaborative effort can be made to provide solutions (Moran, Burson, \& Conrad, 2017). The result of each focus group was analyzed, and the evidence-based process was used to execute the development of a policy. See FADE Model implemented in this quality improvement project below (Figure 3).

In summary, these studies discussed the various complexities of readmissions within 30 days of initial discharge. There is dearth of evidence-based data accounting for successful interventions to decrease 30-day readmissions of postsurgical patients within the southwest healthcare organization. It is apparent that further investigation is needed in 


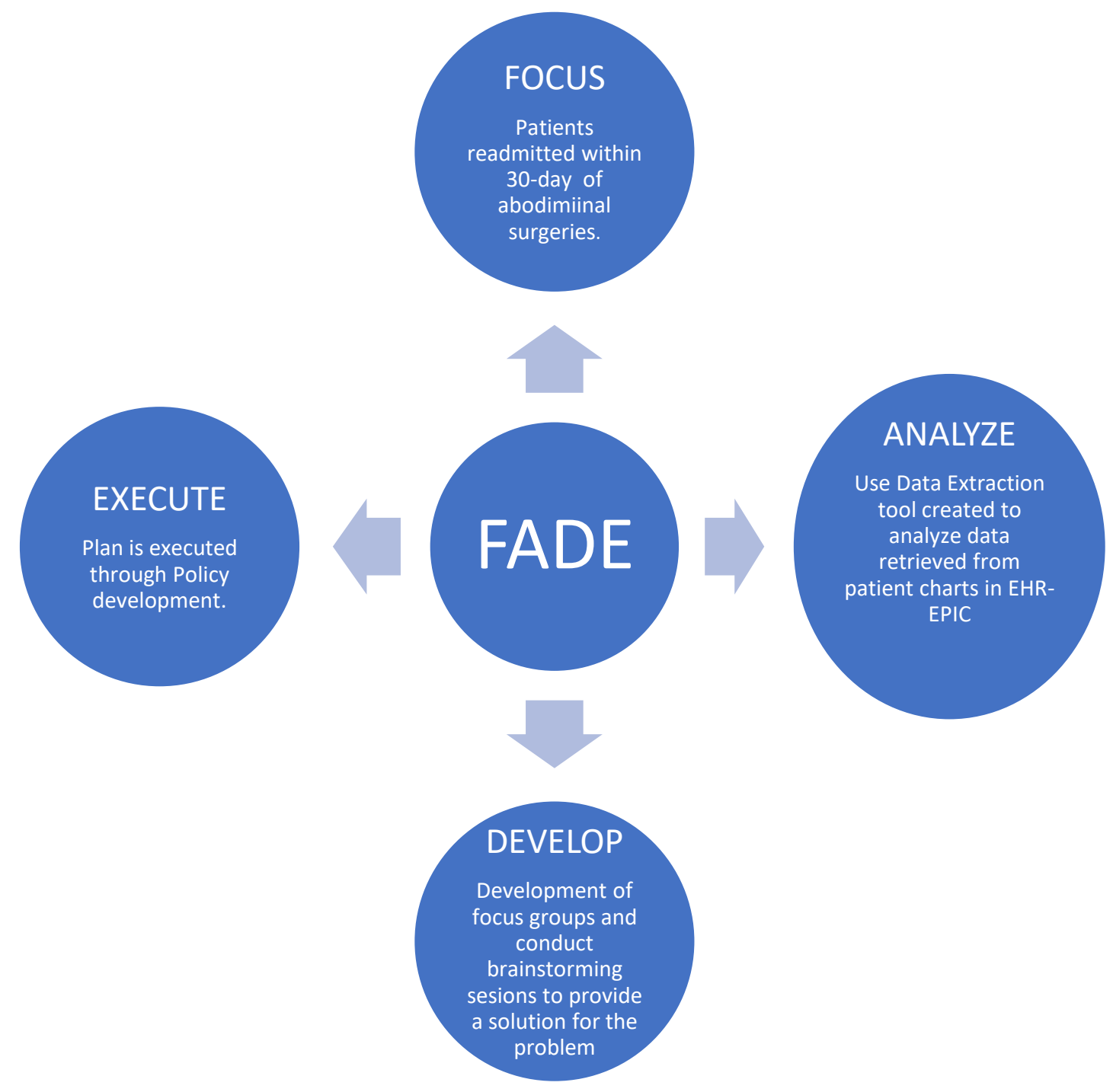

Figure 3. FADE Model of Quality Improvement Applied

addressing ways to decrease factors that cause 30-day readmissions of postsurgical patients. The goal of this project is to contribute to scholarship by developing a policy that focuses on the significant factor found that has contributed to 30-day readmission rates. As a result, the hospital may experience a decrease in readmission of postsurgical patients through relevant policy development. 


\section{CHAPTER 3}

\section{METHODOLOGY}

\section{Approach and Rationale}

This quality improvement project was conducted at a healthcare organization in Southwest Michigan. An Institutional Letter of Agreement was obtained from the Southwest Michigan healthcare system (see Appendix A). Approval from the IRB was obtained from both the Southwest Michigan healthcare system and Andrews University (see Appendix B-D). In this Southwest Michigan healthcare organization, patients are treated for chronic diseases, acute care conditions, and surgical procedures. The healthcare organization includes three hospitals, 51 medical practices, and four walk-in clinics. Various stakeholders are responsible for the operation of the healthcare organization.

Between January 2016 and July 2017, thirty patients were readmitted to the Healthcare Organization within 30 days of discharge following abdominal surgeries and rectal resections. A retrospective chart review was done. Analysis of the patient information collected from the quantitative portion of the project was evaluated using descriptive statistics. A qualitative analysis was implemented for the brainstorming sessions conducted to identify causative factors key stakeholders believe contribute to 30day readmissions of abdominal surgical patients.

A two-question survey was used to gauge the stakeholder's satisfaction on the clarity and comprehension of the policy that was developed. The survey used a five-point 
Likert Scale. The scale ranged from 5 (strongly agree) to 1(strongly disagree) as to the extent to which key stakeholders believe the policy addressed key areas that may cause postsurgical infections (see Appendix J).

The project was completed in two phases. The first phase focused on identifying the main cause of 30-day postsurgical readmissions of abdominal procedures and rectal resections. The second phase involved the development of a policy to address the identified main cause and to reduce the readmission rate. A quantitative approach was utilized for identifying the causative factor through retrospective chart review. A qualitative approach was utilized in the process of policy development.

The retrospective chart review was completed for patients admitted during the period ranging from January 1, 2016, to July 31, 2017. These dates were chosen as recommended report period by CMS for the Healthcare Organization in the study (T. Grove, personal communication, July 9, 2017). All charts for patients who were readmitted within 30-days of initial discharge from an abdominal procedure or rectal resection were reviewed. Data retrieved through chart review of EHRs included: patient's age, sex, marital status, LOS, type of surgery, date of surgery, number of days discharged before return as an inpatient, diagnosis on return, and whether the admission was planned or unplanned.

Patient information was meticulously collected while being mindful of the Health Insurance Portability and Accountability Act (HIPAA) laws concerning privacy. Identification numbers were used to identify patients. Information discovered was shared only with the capstone committee and kept in a secure location. 
After the leading cause of 30-day readmission was identified, the qualitative approach included focus group interviews which helped to determine ways to prevent the major factors identified. Participating in these focus groups are key stakeholders helping to ascertain the main factors in abdominal postsurgical cases contributing to unplanned readmission within 30 days and how to prevent these factors. Informed Consent was obtained from each stakeholder (see Appendix E).

\section{Quantitative Method and Analysis}

Descriptive statistics were used for the data analysis. Descriptive statistics identified evidence-based information to support the project and policy creation. Statistical Package for the Social Science Program version 22 was used to compute data (Statistical Solutions, 2017). The codes that were more specific to the subject healthcare

organization are the DRG codes. The DRG codes specific to the abdominal surgeries for this study were:

DRGs: 329-331 Major Small and Large Bowel Procedures

344-346 Minor Small and Large Bowel Procedures

332-334 Rectal Resection

In this project variables used as the predictors of readmission was the diagnosis with the highest frequency. Only charts with unplanned readmissions were included in this project. Patients with planned readmissions were excluded.

\section{Data Extraction Tool}

The data extraction tool developed for this study was used to record data in two sections. The first section reflects patient data such as age, sex, LOS, DRG, type of surgery, date of surgery, number of days out before return, and diagnosis upon return. 
The second section recorded the reasons for return, including whether the readmission was planned or unplanned (please see Appendix $\mathrm{H}$ ).

Per scholarly literature, there were three frequently occurring causes of 30-day readmissions. These three causes included DVT, dehydration, and infection. All three were involved in the Data Extraction Tool. After completion of the data collection phase of this project, data analysis used frequency charts to identify common data findings that caused 30-day readmissions of abdominal postsurgical patients, and implementation of outcomes in the form of policy development.

Each chart reviewed was assigned a code to prevent exposure of the patient's personal information and to comply with HIPAA requirements. Patient age was included to see what population segments were most frequently readmitted. Sex of the patient was essential to understand what gender was more prone to be readmitted. The LOS was needed to compare the patient stay as an inpatient to the suggested stay provided by policy FY 2014 IPPS/LTCH PPS (CMS, 2017).

Under section 1886(d) of the Patient Protection and ACA, DRG codes are used to classify inpatient discharges and adjust payments accordingly (CMS, 2018). In this project, DRG codes help to identify the type of surgery that was specific to this study. The date of the surgery and the number of days out before return helped to determine if the patient fell within the 30-day readmission period.

\section{Qualitative Method and Analysis}

The purpose of the quality improvement project was to identify stakeholder's perception of the cause and prevention of the main identified factor for 30-day readmission of postsurgical patients in an acute care setting. The goal was to improve the 
care process which would decrease surgical readmissions within 30 days. Thus, the objective was to analyze responses from brainstorming sessions with stakeholders on the identified factor with the highest frequency and to create a policy that would address the primary factor to help decrease 30-day readmissions of postsurgical patients. Existing policies did not specify a standard of care throughout the organization that addressed the common factor identified in this project's findings.

This project used the phenomenological qualitative methodology to understand the potential causes and prevention of 30-day readmission through the lenses of the participants in the focus group discussions. The data analysis process used the methodology of reduction where inherited preconceptions and beliefs of the participants on the causes of 30-day readmissions, whether conscious or unconscious, are uncovered and removed to reveal the real cause. The methodology of reduction is obtained by using the follow-up question "why" to arrive at the root cause. Analysis of responses was used to highlight overarching themes within the brainstorming sessions (Christensen, Welch, \& Barr, 2017).

A convenience sample of 26 key stakeholders shared their thoughts, perceptions, and experiences within the surgical specialty through focus group brainstorming sessions. Since infection was identified as the most frequent cause of readmissions, the four questions guiding the focus group sessions were:

1. In your opinion, what are the causes of postsurgical infection?

2. Why do you believe these are the causes of postsurgical infections?

3. Are there any other causes and categories that we did not discuss?

4. What can we do to prevent the occurrence of infection in our facilities? 
The fishbone tool (see Appendix I) was used to facilitate the process and provide structure and flow (Moran et al., 2017). A series of follow-up questions to responses were asked of participating stakeholders to understand the root cause of the items identified. The group sessions were 30 to 45 minutes in length. Each group comprised of three to five key stakeholders. The focus groups were small enough so that each stakeholder would have the opportunity to speak and large enough to entertain a diversity of opinions among the stakeholders. Data from the focus groups discussions were audio recorded. The stakeholders included two surgeons, two nurse practitioners, six nurse managers, one assistant nurse manager, one postsurgical staff educator, six nurses, and nine medical assistants/nurse's assistants. Discussions were held on-site at the various surgical offices and units.

Analysis of the brainstorming sessions was conducted using a qualitative approach. The audio recordings were transcribed verbatim and read through several times by Miriam Morgan-Skinner, one of the stakeholders, and an independent reader for repeated ideas. Structured paragraphs were used to identify each paragraph of the transcript. These paragraphs were labeled with open descriptive headings for themes that seemed meaningful to the project. Paragraphs were compared to ascertain similarities in meanings of the paragraphs between focus groups.

Clarification of the themes was sought through follow-up group interviews. The healthcare organization staff were informed of the facilitator credentials and the project's quality improvement goals before participation.

The FADE quality improvement model includes four steps that are vital to the success of this quality improvement project. The four steps are methodical and easy to 
follow. The FADE process can also be repeated, so that numerous issues can be recognized, and resolutions can be put in place.

This qualitative analysis of in-depth brainstorming sessions with key stakeholders offered valuable insights about causes believed to be important to the success of policy development and implementation. These insights provided useful lessons to other healthcare leaders pursuing successful development and implementation of a policy on prevention of postsurgical infections. Participation was voluntary and did not affect the staff relationship with the healthcare organization. Participants were not paid. Informed consent was obtained.

\section{Sample Size}

A total of 299 major and minor abdominal surgeries and rectal resections were performed from January 2016 to July 2017. Ten percent of these patients were readmitted within 30 days post discharge. The data were retrospectively retrieved using the Crimson software (D. Wolf, personal communication, October 1,2017), which was used by this subject healthcare organization. Only 30 charts met the criteria for the project, and therefore the sample size was based on all charts meeting the selection criteria. Thirty charts of unplanned readmissions within 30 days following abdominal surgery or rectal resection were reviewed to retrieve data for this project.

In summary, evidence-based data along with healthcare team members suggested causes and prevention methods were incorporated into developing a policy that addresses the factor that is seen as the most common cause of 30-day readmission of abdominal postsurgical patients. The developed policy was shared with the team members who participated in the brainstorm discussions. Their feedback was received through a survey 
of the policy developed. This is another effort to ensure that the project and policy creation receive buy-in from individuals who will be responsible for implementing it (IHI, 2018). 


\title{
CHAPTER 4
}

\section{FINDINGS, DISCUSSION, IMPLICATIONS}

\begin{abstract}
Results
This section includes the findings of this quality improvement project, the analysis of patient data collected, the analysis of brainstorming sessions conducted, discussion, implementation of the nursing profession, plans for dissemination of the project, and opportunities for personal growth. Finally, the ability of the policy regarding future implementation is addressed.
\end{abstract}

\section{Quantitative Findings}

A total of 299 patients who underwent abdominal surgery and rectal resections from January 2016 through July 2017 were identified in the Crimson database. A total of 30 patients were readmitted within 30 days of discharge from their initial surgery hospital, for an overall readmission rate of $10 \%$. Patient demographics, LOS at the hospital, DRG, number of days out before return to the hospital, and diagnosis on the return is reported.

\section{Gender Distribution}

Of the thirty readmissions following abdominal surgery and rectal resection, there were more females than males at 53\% (see Figure 4). Research shows that women have a 


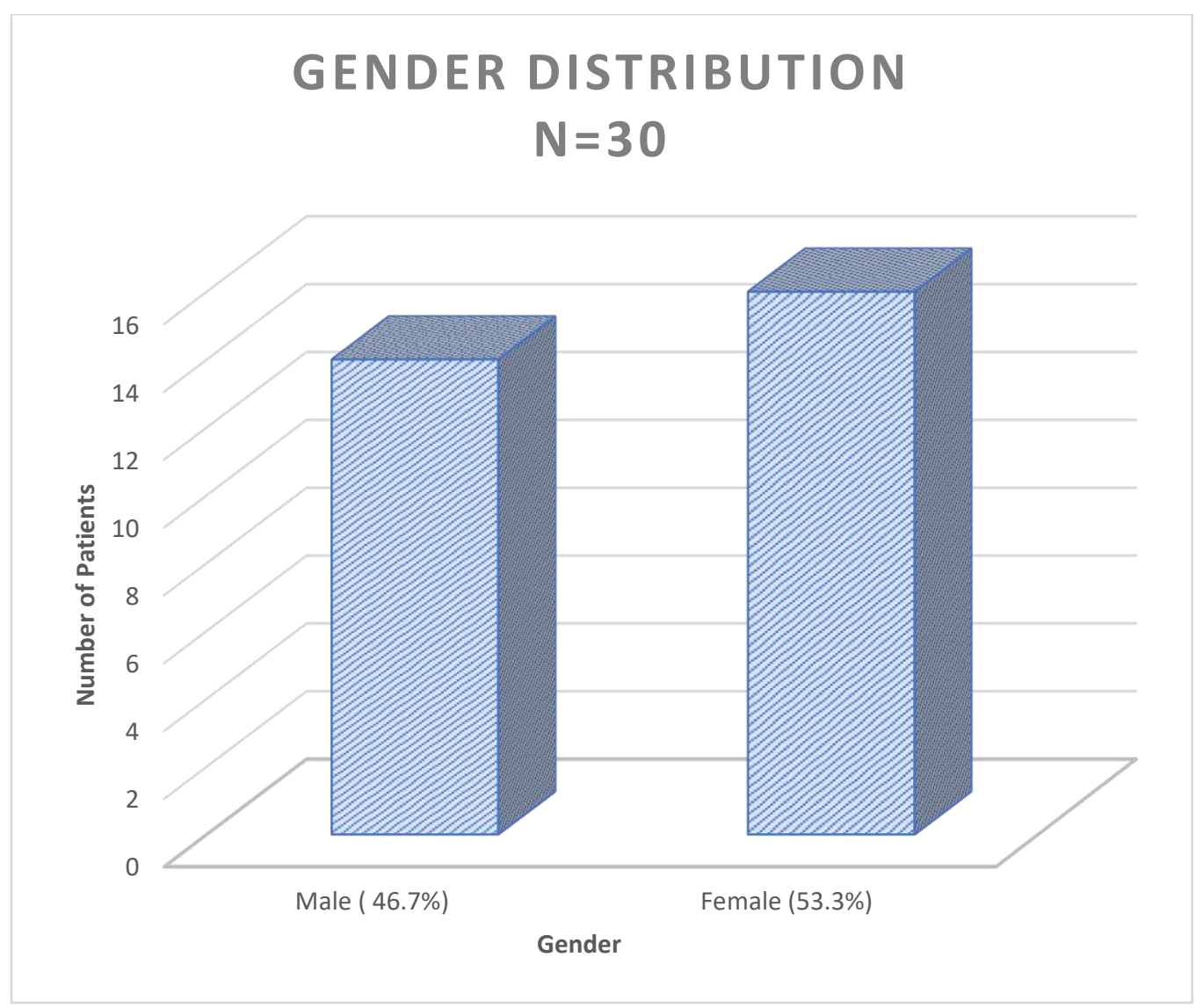

Figure 4. Gender Distribution Bar Chart. This figure illustrates gender distribution.

higher risk of readmission due to more comorbidities and postoperative complications (O’Brien et al., 2017).

\section{Marital Status}

According to demographics on the reviewed charts, more unmarried patients had unplanned 30-day readmissions, at 63\%. This is supported by Moore et al. (2013), where it was found that unmarried patients experienced more readmissions increasingly. The majority of the unmarried patients were never married (43\%). The unmarried category for this project included single, divorced and widowed (see Figure 5). 


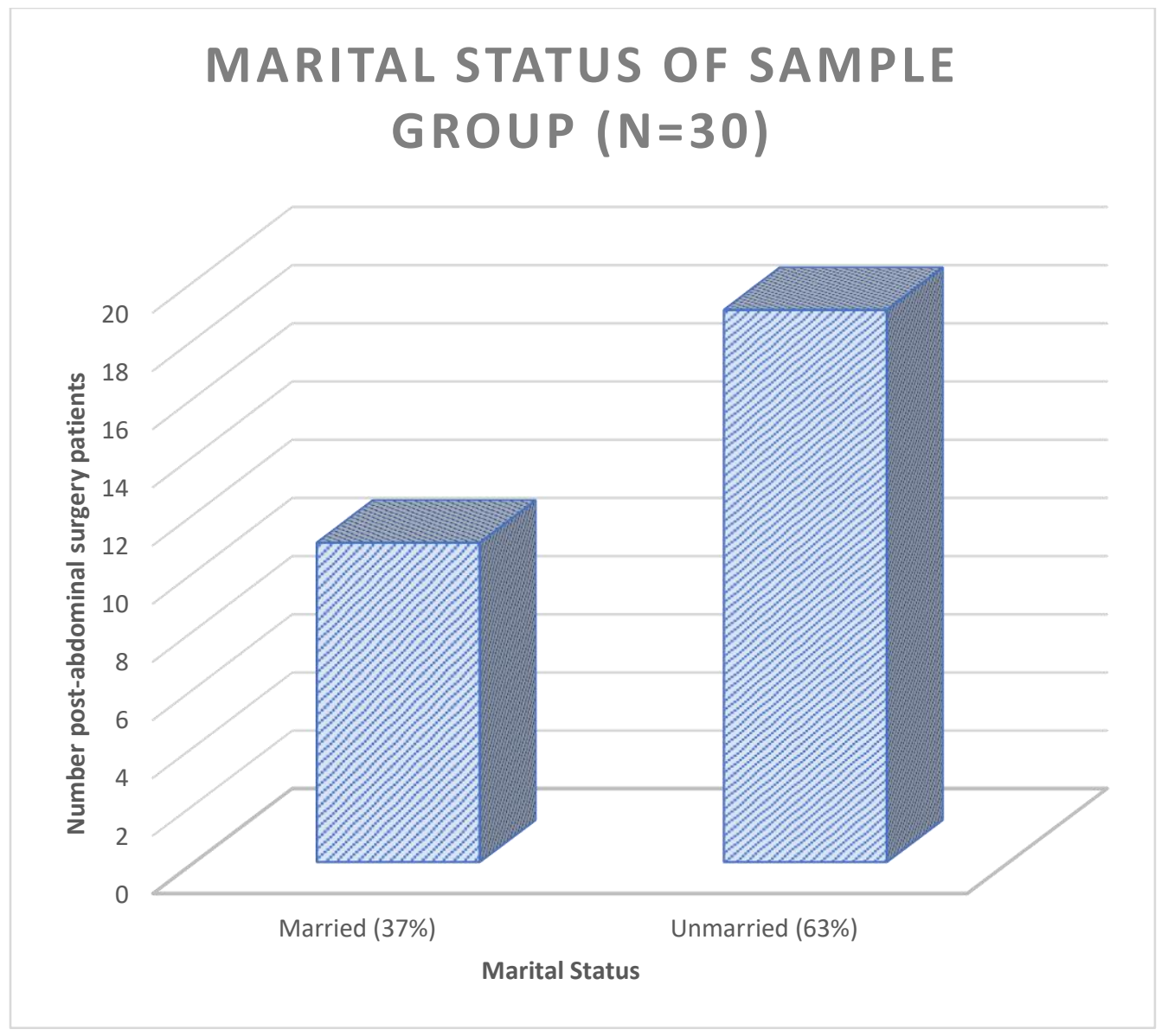

Figure 5. Marital Status Distribution Bar Chart. This figure illustrates the distribution of the marital status.

\section{Length of Stay}

Length of stay ranged from one day to 15 days as an inpatient before discharge. Figure 6 gives the distribution of LOS scores. Seventeen percent of charts reviewed revealed five days of LOS. The average LOS was 7.23 days. Five days were the most occurring LOS among the patients who were readmitted within 30 days.

Ages

Ages range from 37 to 88 years. This project grouped the ages within the study into three main categories to identify trends. Figure 7 shows the age distribution of eight 


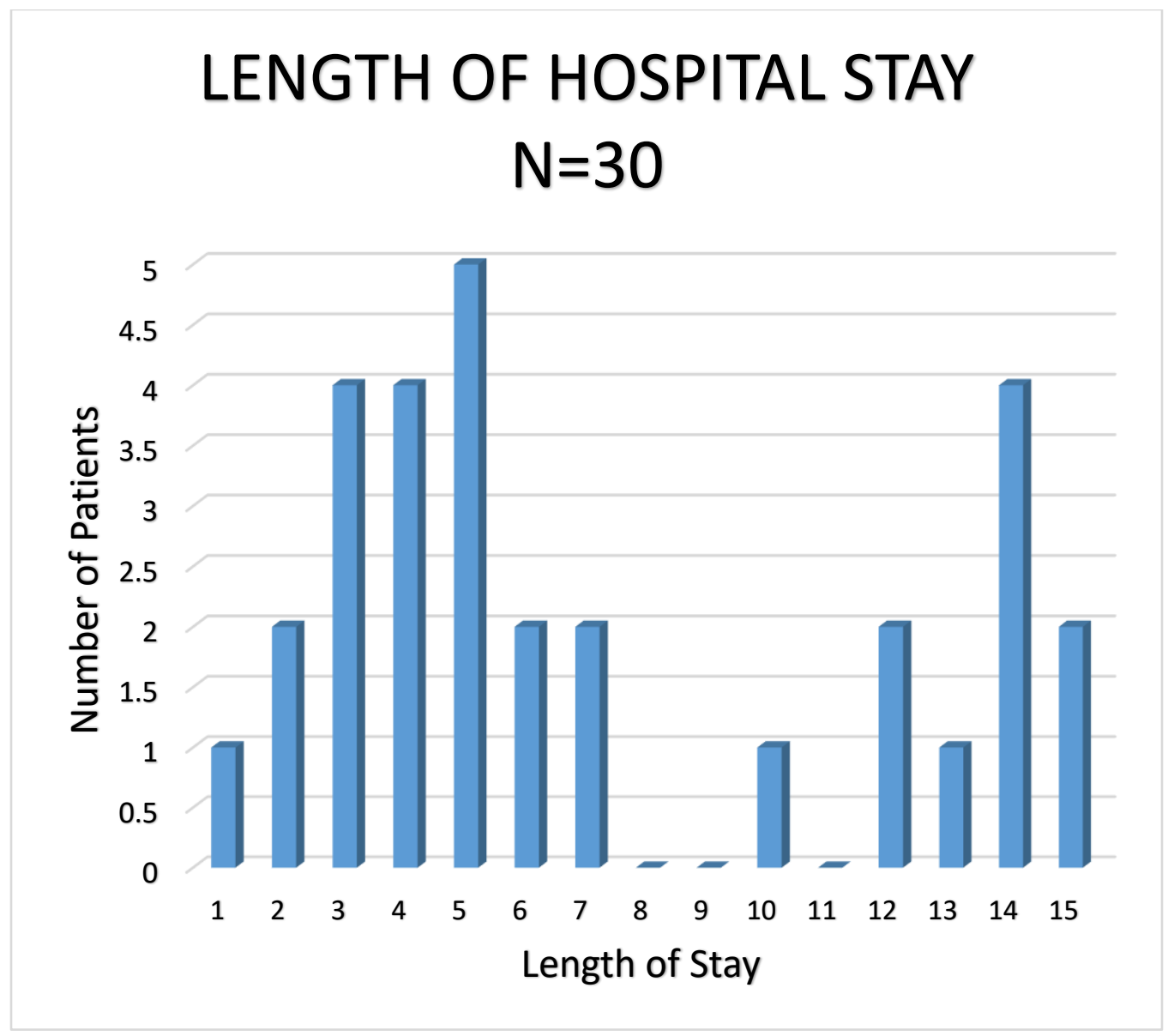

Figure 6. Length of Stay Bar Chart. This figure illustrates the distribution of the initial LOS.

patients below 60 years (27\%), nine patients 60 to 70 years (30\%) and 13 patients above 70 years (43\%). The sample group of over 70 years is identified as having the highest number of readmissions at $43 \%$. Age, in addition to existing comorbidities, may cause patients to experience more complications, which may result in prolonged illness and poor wound healing (Berry et al., 2018).

\section{Average Number of Days Out Before Return}

The number of days out before returning for readmission was sorted into three groups for clarity of data. Descriptive statistics show that more patients were readmitted 


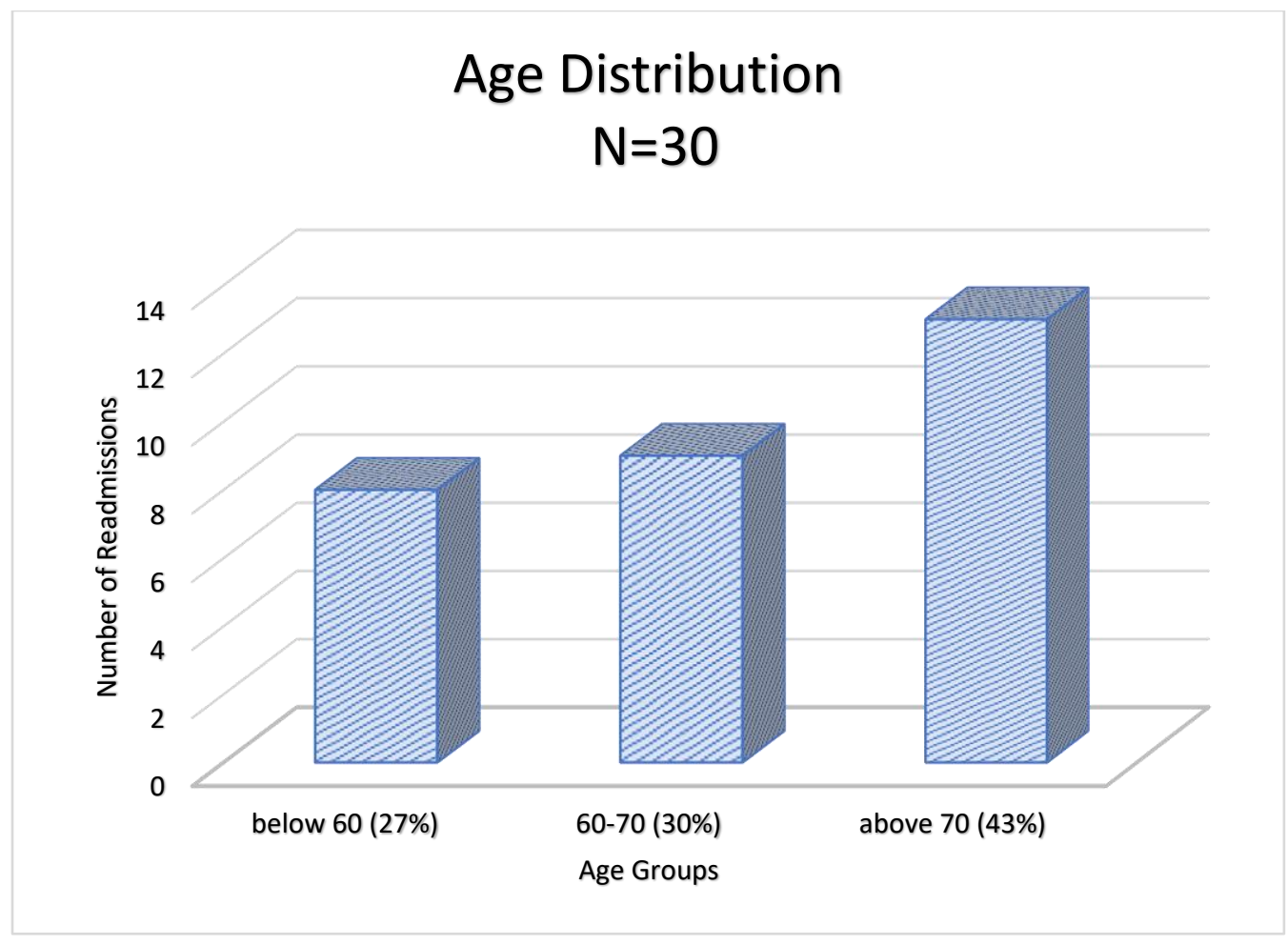

Figure 7. Age Distribution Bar Chart. This figure illustrates the distribution of Ages for patients readmitted within 30-day of discharge.

between 11-20 days post initial discharge at $43 \%$ (see Figure 8 ). Number of days out before return ranged from three days to 27 days. The average number of days out before return was 14.57 .

\section{Diagnosis Related Groups}

Figure 9 shows a frequency distribution of the abdominal surgeries and rectal resections. Findings revealed 17 (57\%) patients readmitted under DRG 330, major small and large bowel procedures with complications. This category of DRGs may include diagnosis; low anterior resection with diverting colostomy, robotic assist colon resection, and exploratory laparotomy, lysis of adhesions. 


\section{NUMBER OF DAYS OUT BEFORE RETURN N=30}

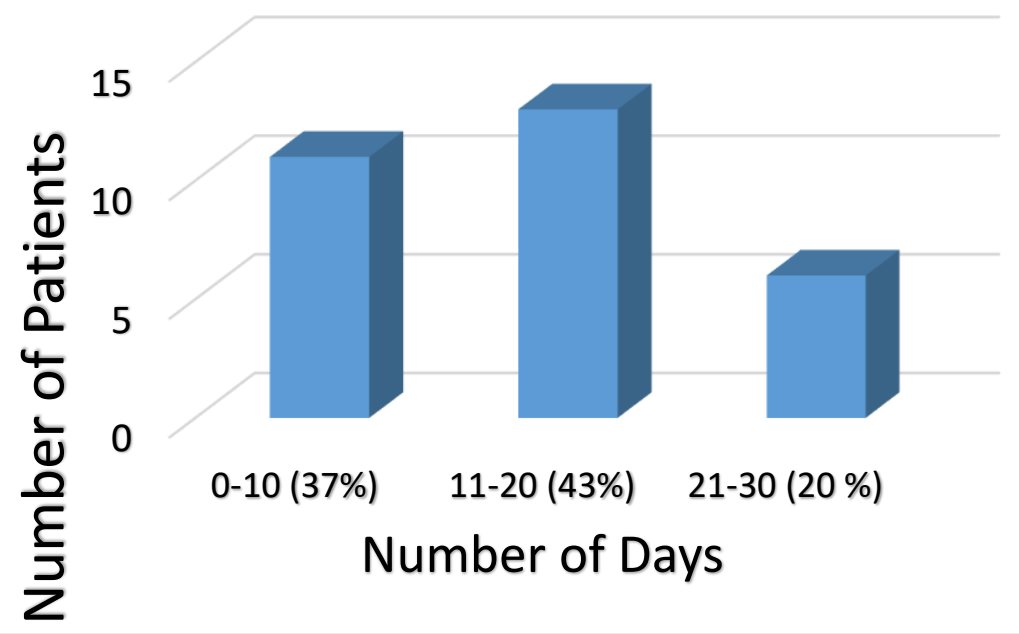

Figure 8. Number of Days Out Before Return Bar Chart. This figure illustrates the number of days the patent was discharged before return.

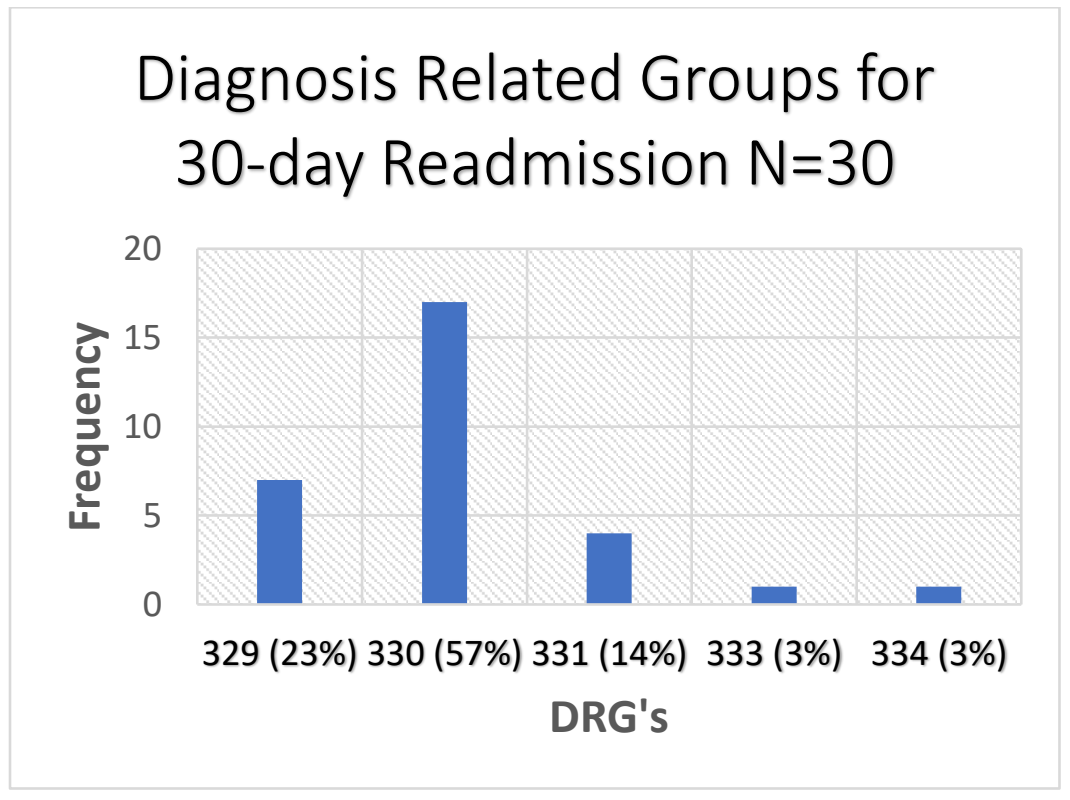

Figure 9. Diagnosis Related Group Bar Chart. This figure illustrates the DRGs specific to this project. 


\section{Infection}

The causes of 30-day readmission based on the return diagnosis of infection (see Table 1) accounted for nearly half of all readmissions (43\%), small bowel obstruction accounted for $10 \%$, and abdominal pain $7 \%$. All other readmissions: nausea and vomiting, stricture of the colorectal region, gastrointestinal bleed, altered mental status, rehabilitation, fall adenocarcinoma of the colon, vaginal and rectal bleeding, hyperkalemia, difficulty breathing, stroke, and urine retention had a readmission rate of three percent.

Table 1

Causes of Readmission Percentage

\begin{tabular}{lcc}
\hline Cause for Readmission & $n=30$ & $\%$ \\
\hline Nausea \& Vomiting & 1 & 3.3 \\
SBO & 3 & 10.0 \\
Ileostomy reversal & 1 & 3.3 \\
Infection & 13 & 43.0 \\
Abdominal pain & 2 & 7.0 \\
GI bleed & 1 & 3.3 \\
Rehab & 1 & 3.3 \\
Altered mental status & 1 & 3.3 \\
Fall & 1 & 3.3 \\
Adenocarcinoma of the colon metastic to liver & 1 & 3.3 \\
Vaginal and rectal bleed-coagulopathy & 1 & 3.3 \\
Hyperkalemia & 1 & 3.3 \\
Difficulty Breathing & 1 & 3.3 \\
CVA (Stroke) & 1 & 3.3 \\
Urine retention & 1 & 3.3 \\
\hline
\end{tabular}




\section{Qualitative Findings}

From the focus group interview questions (see Appendix G), there were six emerging themes for causes of infection. Table 2 shows the emerging themes consisted of the following:

Table 2

Summary of Focus Group Discussion on Emerging Themes

\begin{tabular}{llc}
\hline $\begin{array}{l}\text {-Focus groups } \\
\text { sessions one } \\
\text { through seven. } \\
\text {-Interview } \\
\begin{array}{l}\text { questions one } \\
\text { through three. }\end{array}\end{array}$ & $\begin{array}{c}\text { Themes } \\
\text { Patient Risk Factors }\end{array}$ & $\begin{array}{c}\text { Frequency of } \\
\text { occurrence each theme }\end{array}$ \\
\cline { 2 - 3 } & Patient Education & 7 \\
& Patient Compliance & 6 \\
& Skilled Nursing Facility (SNF) & 4 \\
& Insurance & 1 \\
& & 2 \\
\hline
\end{tabular}

Causes of Postsurgical Infection

In this section, the stakeholders answered discussion questions one through three. Question three was not identified in the title as it was subsumed in questions one and two.

\section{Poor Healthcare Staff Practices}

Identified by six of the seven focus groups, poor hygiene practices by staff is the most noted cause of infection of postsurgical patients. Healthcare staff practices are important in maintaining sterility, cleanliness and an orderly healthcare environment, 
which in part reduces infection. Project participants often encounter situations in which healthcare associates don't practice proper hand hygiene such as hand washing before and after patient care. There are also instances when healthcare staff don't practice proper pre-surgery techniques. As one project participant said, "I see key healthcare staff leave patient's room without washing their hands. I also see poor shaving technique which causes open surfaces on the skin."

Project Participants reported having observed inconsistencies with linen changes and gown changes when patients return from surgery to the inpatient unit. several project participant's cited clinical scenarios that may cause infection of postsurgical wounds include the following: "Some healthcare associates don't change the linens on the patient's bed before they return from surgery. On many occasions, the patients stay on the same linens since they were admitted.”

\section{Patient Risk Factors}

Patient risk factors such as existing comorbidities negatively impact the healing process after surgery. Depending on the comorbidities, patients may be more susceptible to infection of the surgical wound or the wound may never heal. During the group sessions, many risk factors that may cause infection of the surgical wound were identified. Obesity and comorbidities such as diabetes were cited to cause poor wound healing and prolong hospitalization. Project participants stated that, "When a patient is obese there is more tension on the surgical sutures and the gapping areas of the surgical incision may become infected. The tension may also cause the surgical wound to dehisce." 
Comorbidities such as diabetes were also cited as a cause of infection. Diabetes is more debilitating when it is uncontrolled. Even a patient with controlled diabetes can have slow wound healing and be more susceptible to infection. One project participant stated, "There are many occasions when the patient does not take their insulin as prescribed. In fact, I have seen patients take more insulin because they wanted to eat more foods that will affect their insulin level."

\section{Patient Education}

Patient education is the foundation of care. Patient education should start at the commencement of the healthcare relationship. The more the patient understands why their providers complete a process in a certain way, the higher their compliance rate will be. It is imperative that the healthcare team be appropriately educated to be effective when teaching the patients. Patient education is the second most mentioned cause of infection by the project participants. A project participant stated that without proper education:

Patients and caregivers would not know what signs and symptoms to look for when a wound is infected. Patients will not care for the incision the appropriate way by washing and changing the dressings daily. Moreover, if patients are not educated on the process, they will become overwhelmed.

When education is presented the patient may not be able to retain it. This may be because of not being able to process information due to acute or chronic illnesses or the effects of anesthesia post-surgery. A project participant stated:

We need to initiate education the first time the patient visits in the surgery office. This way the patient is already introduced to the information and it will not be as difficult to understand when they hear it after surgery. 


\section{Patient Compliance}

Patients at times are unable to comply with the task set out for them by the healthcare team. These tasks may include using antiseptic soaps or wipes to clean the surgical area before and after surgery, changing surgical site dressing as ordered, mixing and drinking medication before a procedure, or not eating or drinking before surgery. Performing a task takes skill and understanding of the process. Project participants frequently encountered situations where proper prep technique is not followed. An example given was that:

[Two percent] chlorhexidine gluconate antiseptic disposable cloths were not used appropriately by the patient in the areas that they were instructed to be used. Patients would lightly clean a small portion of the area and not the entire area including the groin which may have a culture of bacteria that may go into the wound after surgery.

Improper dressing change is identified as a possible cause of infection. This may stem from missed education opportunities or poor communications between the clinician and the patient or caregiver. An example given by a project participant was:

A patient returned to the physician's office with purulent drainage from the wound. Upon assessment, the patient or caregiver did not pack the wound as directed and as a result drainage from the wound stayed within the cavity of the wound for several days.

Another cited scenario by a project participant was patients are assigned Emmi videos as an electronic information resource to get a better understanding of the process of their surgery and how to prepare for an upcoming surgery. Electronic education materials must cover a broad scope of potential issues in a readily understandable and straightforward way that is simple enough to be used with patients of all ages, races, income and education levels (Hume \& Tomsik, 2014). Many people do not have access 
to the internet or have a computer at home and may not be the best fit of resource for

learning in this population. Project participants narrated personal and patient experiences:

Too many videos are assigned at once, and patients tend not to view them. I was assigned four videos when I was expecting my child; I did not watch any of them as it was information, I thought I knew, and I felt that it was overwhelming.

My patient was assigned a video and she does not have a computer at home. She told me that she would go to the public library but now that she is ill, she will not be able to.

Poor medication compliance was another factor cited during the group sessions. Whatever the reason for poor medication compliance-financially unable to purchase the medication, difficulty in administration due to poor dexterity or noncompliance, can have detrimental consequences. Poor medication compliance may add to the complexity of prolonging wound healing and subsequent wound infection. A clinical scenario given was, "a patient was prescribed antibiotics post surgically. The patient took half of the amount prescribed for half of the time it was to be administered."

Patients are given wound-cleaning equipment and dressing supplies sufficient to last a few days when they are discharged. However, there are questions as to what may have happened to these supplies, as patients are observed with surgical wounds covered with soiled dressings. One clinical scenario given by a stakeholder was:

It is difficult for the patient to be compliant if they do not have the proper equipment. A patient was seen in the office on postoperative day 10 for a follow-up visit and he had the same dressing that they were discharged with.

\section{Skilled Nursing Facilities}

Skilled nursing facilities are a bridge between acute care and home. The environment, however, is less sterile than an acute care hospital as patient personal belongings are encouraged to facilitate a homelike environment. Within the SNF, the 
wound care facilitates more patient involvement which may encourage independence but also introduce infection in the wound if the process is not done accurately. Though skilled nursing homes are an extension of the patient's care, the same level of caution is not maintained in wound care. Project participants believe that:

Discharge to skilled nursing homes, technically a dirty environment, may cause an infection. Due to the uncontrolled environment similar to that of the home environment. Providers may not have a set of eyes on them and we cannot control their hygiene practices. There may also be poor technique practices in SNF too.

\section{Insurance}

Insurance companies play an important role in patient care. Insurance companies determine the duration of care a patient receives as an inpatient and homecare. They also determine if hospitals are reimbursed for their services. Special consideration is not factored in the decision such as whether the patient has comorbidities that promote poor wound healing, such as diabetes, extensive surgical history, or obesity. Project participants stated that, "Insurance companies run our lives. Patients may be assigned between two six post-discharge visits and one dressing change per day by the insurance companies." "This is not sufficient time to teach patients self-care for a favorable outcome."

\section{Preventions of Postsurgical Infection}

Under question four in the qualitative analysis of the brainstorming sessions, "What can we do to prevent the occurrence of infection in our facilities?" there were eight emerging themes (Table 3): 
Table 3

Summary of Preventions Themes

\begin{tabular}{llc}
\hline $\begin{array}{l}\text {-Focus groups } \\
\text { sessions one through } \\
\text { seven. }\end{array}$ & \multicolumn{1}{c}{ Themes } \\
$\begin{array}{l}\text {-Interview question } \\
\text { four. }\end{array}$ & $\begin{array}{c}\text { Frequency of } \\
\text { occurrence each } \\
\text { theme }\end{array}$ \\
\cline { 2 - 3 } & Patient Education & 7 \\
& $\begin{array}{l}\text { Healthcare Staff Education and } \\
\text { Communication }\end{array}$ & 1 \\
& $\begin{array}{l}\text { Discharge Planning } \\
\text { Proper Hygiene /Sterility }\end{array}$ & 2 \\
& Pain Management & 4 \\
& Better Staffing Ratio & 5 \\
& Insurance & 1 \\
\hline
\end{tabular}

\section{Patient Education}

Educating each patient about what to expect during their care is important.

Having an open and effective communication between patient and healthcare team, using simple sentences, is a preventative method that may produce a better patient outcome.

Promoting effective communication through two-way conversations between the healthcare team and the patient or caregivers was identified as necessary as the assessment of the patient's and caregiver's understanding of the information presented is vital in providing effective education. Encouraging return demonstration of wound care techniques by patients and caregivers was also identified as encouraging comprehension and hands-on practice before discharge. 
Question and answer sessions allow the healthcare providers to narrow down the scope of the patient understanding and what they already know. With this assessment healthcare workers can provide individual education when necessary (Hume \& Tomsik, 2014). Education should be presented in a simple way, preferably between a fifth to seventh grade level as recommended by the National Assessment of Adult Literacy (Hume \& Tomsik, 2014). One project participant stated, “The information we share with the patients is simple and is within the guidelines of the state. I also go over the material to make sure that the patient understands what we gave them."

\section{Presurgery Planning Clinic Referral}

Presurgery Planning is a new process whereby patients (mostly high risk) can be referred by their surgeons to be optimized. A participant stated:

Patients have a one time 90 mins session with a Nurse Practitioner. Patients are optimized through education on diet and lifestyle changes. Introduction of nutritional recovery products is also an added benefit. The patient also has an immediate referral to a specialist such as an endocrinologist if their case is too complex for Presurgery planning. Having this resource available to all patients may potentially have a better surgical outcome.

\section{Healthcare Staff Education and Communication}

Effective education of staff is needed throughout the hospital system. Continued education of staff through in-services of new process and equipment is needed to facilitate efficiency in respective areas. Streamlining of education is necessary so that the patient may receive the same education from every department, thus experiencing continuity of care.

Continuity of education is needed throughout the organization. Project participant stated, "there needs to be streamlining of what is expected for specific surgeries across 
the organization. Having the same information offered to every patient is good practice in maintaining consistency may help in preventing infection." An example is given by the project participant of a patient that was discharged from the inpatient setting:

The physician told her orally that she should change her dressing in 24 hours.

However, her discharge instructions state that she should change the dressing every 72 hours. Because of her history of infections, she was cautious and called the doctor's office for clarification.

\section{Discharge Planning}

Discharge planning is necessary to facilitate a smooth transition back in society post-hospitalization. One project participant stated, "discharge planning should commence on the first day the patient is admitted including a multidisciplinary approach."

Project participants observed that proper steps are not taken by patients after discharged. Patients follow up visits or check up with their primary care physician are usually approximately ten days, and a lot can go wrong during that time. Having an earlier follow up after the surgery may allow the surgeon to see potential infection before and be proactive in its prevention. A project participant mentioned, that "postoperative check up should be scheduled sooner than ten days so that the provider can see the healing progression of the surgical incision."

It is crucial that the healthcare team introduce the patients to adequate nutrition before discharge. The benefits of good nutrition promote wound healing and better recovery after surgery. Providing patients with resources such as coupons and samples can point the patient in the right direction and begin the process of healthier meal choices. 


\section{Proper Hygiene}

It is imperative that proper hygiene is practiced by healthcare staff and patients.

Consistent washing of hands technique when entering, performing and leaving patient care areas is important. Project participants mentioned that:

Staff needs to utilize the disinfectant hand foams that are present throughout the organization including patient's rooms and patients should be encouraged to perform hand washing when performing return demonstration of wound care techniques when assisted to the restroom, and before meals.

\section{Pain Management}

Pain management can affect the outcome of a wound. A patient in pain will not be able to adequately care for a wound as their top priority is pain control. Establishing proper pain control early after surgery will enable patients to participate more in their care. Pain management is also noted as having a direct relationship to noncompliance with dressing changes. Project participants argued that:

If patients are in pain, it is difficult for them to learn at an education session. It is also difficult to do their dressing changes, but if they have established a therapeutic level

with their current pain regimen, they are more likely to follow instructions.

Adequate pain control should be established before teaching and return demonstration.

Pain control is also necessary for the home environment if patients are expected to perform proper wound care technique (Hernandez-Boussard et al., 2017).

\section{Better Staffing Ratio}

The staffing ratio of the healthcare team affects the quality of care the patients receive. Without adequate staffing, it is difficult to complete all task effectively. Better staffing ratio will provide patients with health care team members who can spend quality time educating and teaching and proper wound care techniques. Staffing ratio on the 
surgical units was highlighted as a factor that may cause infection of surgical wounds.

One project participant stated that "Nurses have six to seven patients and are too busily concentrating on electronic charting than spending time with patients and conducting adequate skin assessment to catch early signs of infection.”

\section{Insurance}

Insurance companies are very influential in the type and duration of care a patient receives. Acute care and post operation care depends on the type of insurance the patient has, how long they would stay in the post-operative unit and how many days they will be seen by the home care team. A project participant stated:

There need to better insurance policy. Patients sometimes go home with only two days of home care with one dressing change each day. With such a plan it is impossible for the patient to receive adequate homecare to facilitate healing. Homecare should be for a week which includes the further teaching of correct wound care and additional wound care supplies.

In conclusion, of all the causes of infection discussed in the focus groups brainstorming sessions, poor healthcare staff practices were the most commonly mentioned, at all seven sessions. The least mentioned was skilled nursing care facility at one out of seven sessions. Of all the preventions discussed in the focus group brainstorming sessions, patient education was the most mentioned, at seven out of seven sessions, and presurgery clinic, better staffing ratio, and insurance were the least mentioned, each at one out of seven sessions.

\section{Policy Development Process}

Patient education was the most mentioned prevention noted among project participants (see Table 3) and as a result, a policy was developed to address this concern. Also included in the developed policy were some of the other emerging themes from the 
brainstorming sessions. These include healthcare staff education and communication, discharge planning and proper hygiene and sterility.

The policy was developed using the CDC (2018) policy development process. This policy development process has five sections, with continuous evaluation of the process. The core of the process identifies stakeholders and their invaluable contribution through their engagement and education. Section one, "problem identification," showed ten percent of post-abdominal-surgical and rectal resection patients were readmitted within 30 days of initial discharge. Forty-three percent of that population had an infection diagnosis. Section two, "Policy analysis" of a research institution, found eight existing policies. One policy deals with the discharge process for care managers, and the remainder were presurgery planning policies specific to the population they serve. There was no policy on 30-day readmission or postoperative care.

Section three ("Strategy and policy development") reveals that throughout the policy development process there was frequent communication with the various leaders of the respected departments. I facilitated on-site brainstorming sessions with project participants. I educate project participants about the fishbone tool. I shared questions to guide the sessions. I shared the drafted policy with the project participants and met with the policy and procedure committee of the subject healthcare organization.

Section four ("policy enactment") identified resources within the southwest Michigan healthcare organization to help prevent readmissions. Kripalani, Theobald, Anctil, and Vasilevskis (2014) stated that the effect of interventions on readmission rates are related to the number of components implemented. The healthcare organization of study has multiple components to assist in reducing readmission. However, there is a 
disconnect between what the organization has and what the patient receives. Therefore, the policy aims to streamline existing education resources to be more effective for surgical patients.

The drafted policy (see Appendix F) was shared at the second visit with each project participant. The aim was to see if it effectively captured their thoughts, as well as to secure their buy-in further if the policy is implemented. A two-question survey (see Appendix J) was used to capture their perceived satisfaction to the extent they believe I was able to address key areas that may cause postsurgical infection in the policy created on the clarity and comprehension of the policy that was developed. Of the 26 participants, $84.6 \%$ believed that the policy was very clear, and $92.3 \%$ believed that the policy was easy to understand (see Table 4).

Table 4

Stakeholder Survey Result

\begin{tabular}{llll}
\hline Questions & $\mathrm{N}=26$ & $\%$ & $\%$
\end{tabular}

1. Overall, I would rate the clarity of the policy that was developed as

$\begin{array}{lll}\text { Not Clear } & 0 & 0 \\ \text { Fair } & 0 & 0 \\ \text { Unsure } & 0 & 0 \\ \text { Clear } & 4 & 15.4 \\ \text { Very Clear } & 22 & 84.6\end{array}$

2. Was the policy developed easy to understand?

$\begin{array}{lll}\text { Not Easy } & 0 & 0 \\ \text { Fair } & 0 & 0 \\ \text { Unsure } & 0 & 0 \\ \text { Easy to Understand } & 2 & 7.7 \\ \text { Very Easy to } & 24 & 92.3 \\ \text { Understand } & & \end{array}$


Though section five ("policy implementation") was not part of this project, the policy and procedure committee was pleased with the outcome and plans on implementing it within the organization. The committee also wants to include other surgical specialties such as obstetrics within the guidelines of the policy. The overarching success of the policy came when the policy and procedure committee stated that it would be used as a tool for new nursing orientation for the organization.

In summary, a mixed study of both quantitative and qualitative methods has yielded a rich and robust project. Identification of the factors that contribute to 30-day readmissions of abdominal and rectal resection postsurgery was obtained through quantitative analysis. The facilitation of brainstorming sessions on causes and preventions of infection by project participants within the surgical specialty is beneficial in both identifying the frequency of the factors were discussed to help develop policy and receiving their buy-in in for a successful implementation of the policy. The acceptance and implementation of the developed policy by the healthcare organization have proven the success of the project. 


\section{CHAPTER 5}

\section{SCHOLARLY PROJECT FOR DISSEMINATION}

\section{Discussion of Project Results}

This study suggests that communication patterns between healthcare providers and patients are an important and understudied area in the field of events leading to readmission. Prior studies have documented that inadequacies in patient communication by healthcare associates are closely aligned with the returning of postsurgical patients within 30 days of their discharge (Kourkouta \& Papathanasiou, 2014).

The theoretical framework of Dorothy Orem's Self-Care Theory was integrated into this project. The project highlighted areas that lack sufficient education between surgical patients and healthcare providers. The healthcare providers play a vital role in assisting the patient in maintaining an adequate level of self-care. Education through communication is necessary to provide the network of resources needed for education and self-care (Orem, 1995).

The interrelated concepts of Orem's self-care framework; self-care, self-care demands, nursing agency, and self-care agency were identified in this project. Surgeries and preexisting comorbidities may prevent patients from performing adequate self-care such as dressings. The project identified the demand for increased self-care such as the inability to clean wounds properly. The nurse agency, including the healthcare team, need to provide adequate education, necessary tools, and empowerment through booklets, 
technique demonstrations and encourage return demonstrations. Through self-care agency, the multidisciplinary team should provide adequate discharge planning. The team should ensure pertinent information is communicated to the patient including resources in preventing readmission within 30 days.

Descriptive statistics implied by this project revealed that the number of men and women readmitted was about the same -14 men and 16 women. Studies show that women, specifically in the older population, have a higher risk of readmissions. This is due to higher comorbidities than men and more postoperative complications (Mahmoud \& Elgendy, 2018; Yazdanian et al., 2012).

The pool of postsurgical patients readmitted within 30 days included a higher percentage of unmarried patients. The project findings revealed that 11 were married and 19 unmarried (see Figure 5). Marital status is important in the study as it has been shown statistically that survival after major surgery is increased when the patient is married (Neuman \& Werner, 2016). This may be due to having another caregiver who will follow through on the decided treatment regimen and follow-up visits. Being married and living with family both suggest lower mortality and fewer readmissions (Lu et al., 2016).

Premature discharge may lead to readmission within 30 days (Carey, 2014) while prolonging the LOS is associated with a higher risk of readmission (Ansari, Yan, Zou, Worth, \& Barbaro, 2018). Therefore, having a reasonable LOS for acute care patients are shown to be favorable in preventing readmission. Patients may be able to reach a higher level of stability as well as enjoy more time for education about expectations concerning their postdischarge behavior (Bartel, Chan, \& Kim, 2016). 


\section{Focus Groups Brainstorming Themes \\ from Qualitative Results}

The themes used in the qualitative analysis were derived from the stakeholder's opinions as to the causes and preventions of infection in postsurgical patients. These themes were chosen because they were most frequently mentioned by stakeholders throughout the focus groups brainstorming sessions. The stakeholders seemed passionate about the potential causes and possible preventions of a return diagnosis of infection and cited multiple items that may contribute to both categories.

\section{Infection}

Infection was identified as the most significant factor that causes 30-day readmission within the Southwest Michigan organization and has the highest percentage (43.3 percent) of readmissions (see Table 1). According to Demidova-Rice, Hamblin, and Herman (2012), over 11 million individuals are affected by acute wounds annually. With such a significant population size, it is evident that the process of care for a wound may lead to an infection.

The wound healing process goes through several stages; vascular response, proliferation, and repair and maturation and remodeling (Demidova-Rice et al., 2012). If this process is disrupted due to the introduction of bacteria, or existing comorbidities, the healing process will be altered. Healthcare stakeholders need to adopt a different approach to educating themselves, peers and patients on how to provide care that will result in a better patient outcome. 


\section{Implications}

According to the evidence-based literature, hospital reimbursement is adjusted depending on the number of readmissions. It is a significant issue that is not showing signs of decreasing among abdominal surgical patients. The development of a policy to decrease infection could potentially reduce the 30-day readmission rate of abdominal postsurgical and rectal resection patients. Development of a policy to decrease infection in abdominal postsurgical patients may have an impact on the overall readmission rate.

The data obtained from this project and recommendations made by key stakeholders may be utilized to make changes in the education process for both the patient and the healthcare team. Education changes can be initiated at the initial visit, during hospitalization, and after discharge. These changes may strengthen the effectiveness of the developed policy. Even though this quality improvement project is done on a small scale, it could highlight the common readmission diagnosis, raise awareness, and change the approach to preventing infection.

\section{Impact on Policy}

The policy is essential at all stages of the patient care process, and public health professionals play an important role in the policy development process. This is achieved by conducting policy analysis, communicating findings, developing partnerships, and promoting and implementing evidence-based interventions (CDC, 2018). These skills assist in the policy development by the author. The agreed-upon policy provided the framework for streamlining the educational process in the southwest healthcare organization. Ensuring buy-in from key stakeholders to the new policy helped to achieve a better understanding among the surgical healthcare team. 


\section{Impact on Nursing Practice}

As a Doctor of Nursing Practice (DNP), it is imperative that I become involved in shaping healthcare policy and promoting advocacy (Chism, 2016). I will be able to improve the educational process of potential surgical patients. Enhancing the care of these patients from their initial visit to their discharge is important for the patient, the healthcare team, and the healthcare organization. My goal is to help achieve better optimization through effective education for the entire hospital experience. Healthcare providers should be committed to improving the health outcome of surgical patients.

Readmissions due to infection within thirty days following abdominal surgery have caused poor experiences for patients and withholding of reimbursements by CMS. The development of a policy that addresses the prevention of postsurgery infection will bring about a new awareness that education in its simplest form is important for each patient. Therefore, through the development and implementation of this policy for abdominal surgeries, other surgical specialties may be motivated to maintain an improved standard of care.

As a DNP graduate, my academic role is to interpret evidence into practice. My leadership and communication skills have prepared me for the process of developing an infection prevention policy. Collaborating with other healthcare team members to build upon my quality improvement project has been a rich experience. This experience will enable me to be persuasive in other evidence-based studies. Sharing my experiences and the lessons learned with DNP students in the process of writing their capstone projects may prove helpful in their process. Poster presentations, presentation to healthcare groups, and publishing this quality improvement project will further share the experience. 
Furthermore, I can positively improve the education process of potential surgical patients throughout their experience. In the end, this quality improvement project will benefit surgical patients, the healthcare team that cares for the surgical patients, and ultimately the healthcare organization.

\section{Project Strengths, Limitation, and Recommendation}

To my knowledge, this is the first set of brainstorming sessions examining surgical team perspectives on reasons for unplanned 30-day hospital readmissions. I gathered information from the healthcare team with a range of clinical experience, all of whom provide direct patient care with surgical patients. My data came from healthcare team members at six surgical offices and departments varying locations and patient population, allowing me to identify a broad range of factors contributing to postsurgical infection.

The creation of the policy on the prevention of postsurgical infections and its evaluation required effective teamwork. The team approach strengthened the policy and supported its development. The evidence used for this quality improvement project came from evidence-based literature. Collaboration among the healthcare team at the southwest Michigan healthcare organization contributed to the support of the policy development. The healthcare team worked well together respecting other viewpoints during the brainstorming sessions. Effective communication skills played an important part in the flow of the process.

Developing a new surgical education policy had a few limitations. The retrospective chart review of patients with 30-day readmissions following abdominal surgery and rectal resection showed a minimal return of 10 percent, a convenience 
sample of 30 . The project was not able to reflect a true sample size as statistically calculated. This author identified cases for review using convenience sampling of a specific set of surgeries readmissions at a single healthcare system. These factors may limit the generalizability of the findings.

\section{Analysis of Self as a Professional}

As a DNP, it is imperative that I perform self-analysis. This process of selfanalysis will enable me to reflect on my interpersonal and professional growth. I often reflect after writing each chapter by communicating with my committee members and family. Frequent reflection afforded me more understanding on the direction I should take with the project. Even though I experienced detours along the process, I was able to use skills I have attained as a scholar, supervisor, and project developer to overcome them.

\section{Analysis of Self as Scholar}

This quality improvement project process has prepared me to apply evidencebased findings to develop policies. As a scholar, I have made improvements to the education of surgical patients and the healthcare environment to facilitate better outcomes for the patients. The learning experience has enhanced my ability to effect change in the healthcare setting through policy development. This accountability has helped to improve patient outcome throughout their care experience. My project was founded on the Essentials for Doctoral Education for Advanced Nursing Practice. The essential that influenced my project was Essential V. This essential helped me to develop a policy on infection prevention that will facilitate a change in the practices of healthcare team members and patient outcomes. 


\section{Analysis of Self as Project Developer}

With each quest during the process of this project, I am provided with pertinent information that enabled me to progress successfully. As a project developer, I have learned the process to afford positive changes through policy creation. Working with the healthcare team to identify retrospective 30-day readmissions with infections and brainstorming causes of postsurgical infections has made me more aware of the effects that impact evidence-based care. I can communicate with others on potential causes of readmissions within thirty days post discharge. This experience has improved my communication skills, broaden my understanding of potential ways to educate patients and healthcare team, and improve my professional development. I look forward to my implementation of the policy and its outcome by affecting change in healthcare.

\section{Meaning of Project for Future Professional Development}

The 30-day readmission rate has proven to be a revolving door problem in the inpatient healthcare setting. Reimbursement is withheld until adequate evidence proves that readmission was necessary and was not a result of subpar patient care. The policy addressing education to reduce infection of postsurgical patients is now complete and will be implemented by the southwest Michigan health care organization within the next year. However, it is imperative that the author see the process and evaluation through by following 30-day readmission of abdominal postsurgical rates six months after policy implementation. The topic of readmission is important to me, and I will continue to be a part of the healthcare focus team after program completion. 


\section{Impact on Practice}

Many patients are not assessed for their level of understanding or education at their initial visit at the Southwest healthcare system. The omission of effective communication during the presentation of healthcare information to patients may lead to misunderstanding of self-care practice. If the information is given to patients or caregivers without proper education, return demonstration and having the patients report what they understood from the presentation to gauge a patient's understanding may lead to improper practices in wound care which will result in infection and ultimately readmission.

The quality improvement project resulted in a policy creation to prevent wound infection as a cause of unplanned 30-day readmissions in abdominal surgical patients. The policy will help ensure that effective education is done at a literacy level simple enough for patients to understand the instructions given. The impact of the policy will be measured six months after policy implementation. This is because readmission rates are evaluated every six months (D. Wolf, personal communication, September 18, 2017) at this southwest healthcare organization. The analysis within six months of implementation will gauge the effectiveness of the policy and may require remedial education of stakeholders if a positive result of a decrease in the rate of postsurgical readmissions are not observed. The policy may apply to other surgical practices and demonstrate the importance of DNP influence in healthcare.

\section{Plan for Dissemination of Project}

It is incumbent on the project developer to think globally about disseminating this evidence-based project as it has the potential to change the practices of healthcare 
associates and in turn the experiences of the patients. The target audience that I intend to influence will guide my decision to choose a specific journal. Therefore, Journal for Healthcare Quality (JHQ), the American Journal of Surgery (AJS), and the Journal of Nurse Practitioners (JNP) will be effective journals to reach the target population of practicing healthcare providers. The decision for choosing JHQ, AJS, and JNP journals to disseminate this project is twofold. First, it may bring awareness of quality improvement changes in healthcare with the potential to increase patient satisfaction and subsequently increase reimbursements, as well as improve outcomes. Secondly, other healthcare organizations may be able to repeat the study in their practices, making modifications when possible.

In summary, this project was generated because of the need to identify factors contributing to 30-day readmissions of abdominal and rectal resection postsurgical patients. Through literature analysis and research, variables were identified that contributed to 30-day postsurgical readmission. This project implemented a mixed method to analyze the data. From the quantitative analysis, infection was the most frequently noted cause of readmission within 30 days after initial discharge.

Qualitative analysis of the data conducted focus group brainstorming sessions with key stakeholders within surgical specialty. From the seven brainstorming sessions completed, there were six emerging themes that identified causes of infection in post abdominal and rectal resection surgeries: Poor healthcare staff practices, patient risk factors, patient education, patient compliance SNF, and insurance.

The brainstorming sessions also identified eight emerging themes on ways to prevent infections: patient education, presurgery planning clinic referral, healthcare staff 
education and communication, discharge planning, proper hygiene and sterility, pain management, better staffing ratio, and insurance. The prevention most frequently mentioned during the sessions was patient education. The policy developed contained guidelines that address patient education, healthcare staff education and communication, discharge planning, and proper hygiene and sterility.

A policy was developed to address a significant portion of the identified causes. Information received from the study was beneficial in creating the appropriate policy to effectively decrease the percentile of 30-day postoperative readmission. This policy will not only benefit the facility where the research will be done, but it will also become a resource for other institutions and scholars.

\section{Spiritual Component}

Readmission has proven to be an important indicator of inadequate patient care. Through diligent research the DNP will identify areas to improve patient care under the guidelines of the DNP essentials. For this project it is prudent for the DNP to identify ways to help decrease the incidence of 30-day readmission. The implementation of policies that will mandate adequate education before during and after surgical procedures will be beneficial in this venture.

As the DNP continues to seek the best interventions for a better patient outcome, they are reminded that the wisdom and knowledge come from God and if we ask Him, it will be generously granted unto us (James 1:5, English Standard Version). As the Practitioner continues to seek knowledge and understanding from Go to treat their patients, they are reminded that, "blessed is the one who finds wisdom, and the one who 
gets understanding for the gain from her is better than gain from silver and her profit better than gold" (Proverbs 3:13, English Standard Version). 
APPENDIX 
APPENDIX A

INSTITUTIONAL LETTER OF AGREEMENT 


\section{\& Lakeland Health}

June 15, 2017

Dear Dr. Jochebed Bea Ade-Oshifogun:

As the Lakeland Health Interim Chief Nursing Officer, I approve and submit this letter of supportive intent on behalf of Lakeland Medical Center for Miriam Morgan-Skinner, RN Doctor of Nurse Practice (DNP) student. She is proposing to conduct a Capstone Process Improvement Project at Lakeland Medical Center - St Joseph, Michigan. This proposed project will be a retrospective study, reviewing 100 closed patient records ranging from 2015-2016. The goal is to record predisposition of co-morbidities present upon discharge and which co-morbidities were indicated in a 30-day re-admission.

The Capstone Project is based on the implementation of a policy or revision of an existing policy based on 30-day readmission reduction. This letter is not a binding agreement nor supersedes the Internal Review Process of Andrews University and Lakeland Medical Center.

Kindest of Regards,

Debbie Lull

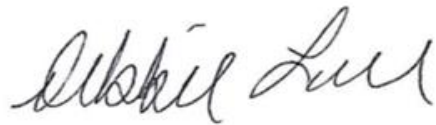

Debbie Lull, RN, BSN, MSA, FACHE

Interim VP, Patient Care Services \& CNO

Lakeland Health

1234 Napier Ave

St. Joseph, MI 49085 
APPENDIX B

INSTITUTION IRB LETTER OF APPROVAL 


\author{
Lakeland Hospitals \\ Niles and St. Joseph IRB \#1
}

To:

\author{
Miriam Morgan-Skinner \\ 9124 George Ave. \\ Apt. 38 \\ Berrien Springs, MI 49103
}

Re: $\quad$ Factors Contributing to 30-Day Re-Admission

Rate in Post-Surgical Patients: A Re-

Evaluation of Hospital Policies and Proposal for Change

Date: $\quad$ July 28,2017

This is to inform you Lakeland Hospitals Niles and St. Joseph, IRB\# 1 has approved the above research study to be conducted at Lakeland Health Care. The study has been determined to be exempt from review according to our Standard Operating Procedures and Claim of Exemption Checklist.

Please send a final report upon completion of the study.

The IRB operates in compliance with GCP and applicable laws and regulations to the best of its knowledge. The IRB consists of members of the clinical and scientific communities, non-scientists, as well as members of the community as required by Federal regulations to assure a fair and thorough review process.

Lakeland Hospitals Niles and St. Joseph, IRB\# 1 is registered with the Office for Human Research Protections (OHRP). Please refer to OHRP's Web site for at http://ohrp.osophs.dhhs.gov/irbasur.htm for a list of registered IRBs.

Please call me if you have any questions. The IRB wishes you success with this research.

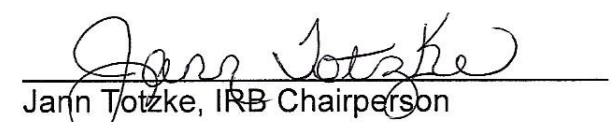

Lakełand Hospitals Niles and St. Joseph, IRB\# 1

\footnotetext{
Lakeland Hospitals at Niles and St. Joseph,IRB

Marie Yeager Cancer Center O St. Joseph, MI 49085-1258 (269)556-7168

www.lakelandhealth.org
} 
APPENDIX C

UNIVERSITY IRB LETTER OF APPROVAL 


\section{Andrews $₫$ University}

August 16, 2017

Miriam Morgan-Skinner

Tel. 269-240-0966

Email: wewee1320@yahoo.com

RE: APPLICATION FOR APPROVAL OF RESEARCH INVOLVING HUMAN SUBJECTS

IRB Protocol \#:17-111 Application Type: Original Dept.: Nursing (DNP)

Review Category: Exempt Action Taken: Approved Advisor: Jochebed Ade-Oshifogun

Title: Factors Contributing to 30-day Re-admission Rate in Post-Surgical Patients at a Community

Hospital: A re-evaluation of Hospital Policies and Proposal for Change.

Your IRB application for approval of research involving human subjects entitled: "Factors Contributing to 3o-day Re-admission Rate in Post-Surgical Patients at a Community Hospital: A re-evaluation of Hospital Policies and Proposal for Change" IRB protocol \# 17-111 has been evaluated and determined Exempt from IRB review under regulation 46.101 (b) (4). You may now proceed with your research.

Please note that any future changes (see IRB Handbook pages 11-12) made to the study design and/or informed consent form require prior approval from the IRB before such changes can be implemented. Incase you need to make changes please use the attached report form.

While there appears to be no more than minimum risks with your study, should an incidence occur that results in a research-related adverse reaction and/or physical injury, (see IRB Handbook pages 12) this must be reported immediately in writing to the IRB. Any research-related physical injury must also be reported immediately to the University Physician, Dr. Katherine, by calling (269) 473-2222.

We ask that you reference the protocol number in any future correspondence regarding this study for easy retrieval of information.

Best wishes in your research.

Sincerely,

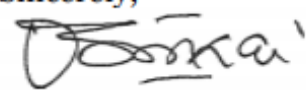

Mordekai Ongo

Research Integrity and Complaince Officer

Institutional Review Board - 4150 Administration Dr Room 322 - Berrien Springs, MI 49104-0355

Tel: (269) 471-6361 Fax: (269) 471-6543 E-mail: irb@andrews.edu 
APPENDIX D

UNIVERSITY IRB MODIFICATION APPLICATION 


\title{
Andrews 0 University
}

June 18, 2018

Miriam Morgan-Skinner

Tel. 269-240-0966

Email: wewee1320@yahoo.com

\begin{abstract}
RE: APPLICATION FOR APPROVAL OF RESEARCH INVOLVING HUMAN SUBJECTS IRB Protocol \#:17-111 Application Type: Original Dept.: Nursing (DNP)

Review Category: Exempt Action Taken: Approved Advisor: Jochebed Ade-Oshifogun Title: Factors Contributing to 30-day Re-admission Rate in Post-Surgical Patients at a Community Hospital: A re-evaluation of Hospital Policies and Proposal for Change.
\end{abstract}

Your IRB modification application for approval of research involving human subjects entitled: "Factors Contributing to 3o-day Re-admission Rate in Post-Surgical Patients at a Community Hospital: A re-evaluation of Hospital Policies and Proposal for Change" IRB protocol \# 17-111 has been evaluated and determined Exempt from IRB review under regulation 46.101 (b) (3). You may now proceed with your research.

Please note that any future changes (see IRB Handbook pages 11-12) made to the study design and/or informed consent form require prior approval from the IRB before such changes can be implemented. Incase you need to make changes please use the attached report form.

While there appears to be no more than minimum risks with your study, should an incidence occur that results in a research-related adverse reaction and/or physical injury, (see IRB Handbook pages 12) this must be reported immediately in writing to the IRB. Any research-related physical injury must also be reported immediately to the University Physician, Dr. Katherine, by calling (269) 473-2222.

We ask that you reference the protocol number in any future correspondence regarding this study for easy retrieval of information.

Best wishes in your research.

Sincerely,

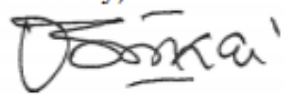

Mordekai Ongo

Research Integrity and Complaince Officer 
APPENDIX E

INFORMED CONSENT 


\section{Informed Consent Form}

\section{Principal Investigator: Miriam Morgan-Skinner}

\section{Introduction}

The goal of this study is to explore possible factors that cause infections that lead to readmission within 30-day- readmission of postsurgical patients.

In this study, you will be asked to participate in a 30-minute taped discussion on factors that may lead to 30-day readmissions of surgical patients.

\section{Before we start, you should know the following:}

- Taking part in the research is completely voluntary.

- There is no compensation for participating in this study but the satisfaction that you are contributing to information to identify factors of 30-day readmissions of surgical patients.

- The focus group will take about 30 minutes.

\section{Nature of the Study:}

- The study will involve participating in a focus group with the investigator.

- Your name will never be recorded along with what you say in the focus group.

- What is learned from the focus group may help us develop ways to reduce 30-day readmissions of surgical patients.

- If you choose to participate in the study, we will ask you to sign this form.

- You can decide not to participate in the study after you have given permission.

\section{Risk for being in the Study:}

This study has minimal risk of sometimes feeling uncomfortable with some of the topics discussed. You will use a pseudo name, and the information you provide will not be linked to your identity. I am interested in your opinions about the factors. You can also choose to exit the focus group if you feel uncomfortable.

\section{Benefits of the Study:}

This study will have no specific benefit to you. However, it will provide information that may improve surgical readmission outcome for the organization.

\section{Confidentiality:}

Study data will be kept in a locked cabinet. Names and other identifying information from the study will not be included. Your real name will not be identified with any report of this study. 


\section{Contact and Questions:}

This study is being conducted by Miriam Morgan-Skinner Andrews University

Berrien Springs, Michigan. If you have questions or concerns about this study, please contact Miriam Morgan-Skinner at 269-240-0966 or the chair of this research Dr. Bea Ade-Oshifogun at 269-471-3363

If you have questions about your rights as a part of the focus group, contact Cindi Zech IRB Specialist Lakeland Hospitals, 269-556-7168 or via email:

czech@lakelandhealth.org. Mordekai Ongo, Research Integrity, and compliance officer Andrews University, 269471-6361 or via email: irb@andrews.edu

\section{Documentation of Informed Consent}

Please sign only if you agree to the following:

$>$ I agree to participate in the study review

$>$ I understand the goals, benefits and potential risk of the study

$>$ I have discussed any questions I have about the study.

$>$ I have read and comprehend the above agreement.

Signature of Participant

Date

Signature of Researcher

Date 
APPENDIX F

LAKELAND HEALTH 
Readmission Policy

Policy -Procedure

Subject:

Prevention of wound infection as a cause of unplanned 30-day readmission in abdominal surgical patients.

Submitted by: $\quad$ Miriam Morgan-Skinner BSN

References: $\quad$ See reference at the end of the policy

\section{PURPOSE}

To prevent post abdominal surgical wound infection and increase effective communication between;

a) The healthcare team members who provide safe care.

b) The patient and healthcare team regarding proper care of surgical incisions, to provide patients with instructions to prepare for surgery and to eliminate postsurgical infections.

SCOPE

Southwestern Medical Clinic Surgical Specialties-St. Joseph

Lakeland General Surgery-St. Joseph

Lakeland General Surgery-Niles

Presurgery Planning Clinic- St. Joseph

Post -Surgical Unit- St Joseph

Operating Room-St Joseph

Post-anesthesia Care Unit 


\section{POLICY}

It is Lakeland's policy that patients undergoing abdominal surgery, and rectal resection receives clear and simple communication through verbal, visual and written education resources regarding care of surgical incisions.

\section{PROCEDURE}

Assess Patient and Caregiver's Knowledge.

- Assess the patient and family readiness to learn and barriers that may prevent effective wound healing.

Educate and Reinforce Regarding Safe Wound Care Practice

- Use the "Prepare for your Surgery" folder with all outpatients being scheduled for surgery. Review information in the "Prepare for Surgery "section on page 2 and "Preventing Infection" section on page 3-4.

- Before surgery instruct the patient shower daily, three days before surgery, use a clean towel each time, wear clean clothes after showering and sleep on clean linens.

- Talk with your healthcare provider about stop smoking.

- Encourage family members who may be sick or have an infection to wait to visit the patient until they are recovered.

- Patients should perform a return demonstration of how to clean the wound at the time of education with the healthcare team.

- Keep dressing supplies in a clean area

Provide Patient-Centered Education.

- Initiate patient education at the initial visit.

- Share "Getting Ready for your Surgery" handout with patients on the surgical units before surgery.

- Provide teaching instruction to the patients at the literacy level of the $5^{\text {th }}$ grade as much as possible.

- Present educational information in the learning style that best fits the patient which was identified during assessment. 
- Assess patient social network and resource available in the community and provide resources that are available.

- Utilizing Patient Education videos (Emmi) such as Wound Care: Surgical Wounds; Wound Care: Chronic Wounds; Patient Satisfaction: After Discharge Expectations; Surgical Site Infection Prevention; Indwelling Urinary Catheter: Female Version; Indwelling Urinary Catheter: Male Version throughout a patient's experience.

\section{EVALUATION}

All educational materials and resources will be written at a $5^{\text {th }}$-grade level as much as possible to facilitate various reading levels. Healthcare providers will assess the level of education so that appropriate resources are provided for the individual patient. All patients will commence the education process at the initial meeting with the healthcare team. Patients will be assessed for appropriate knowledge and capacity to perform adequate wound care. Modifications of the policy are made based on evaluation which continues throughout the life cycle of a policy.

\section{REFERENCES}

Agency for Healthcare Research and Quality. (2014). Conditions with the largest number of adult hospital readmissions by payer, 2011.Retrieved from https://www.hcupus.ahrq.gov/reports/statbriefs/sb172-Conditions-Readmissions-Payer.pdf

Bastable, S. B., Gramet, P., Jacobs, K., \& Sopczyk, D. L. (2011). Health professional as educator: Principles of teaching and learning. Sudbury, MA: Jones \& Bartlett Learning, LLC

Center for Medicaid and Medicare Services (2018). Hospital-wide (all-condition) 30-day risk-standardized readmission measure: Draft measure methodology report. Retrieved from https://www.cms.gov/Medicare/Quality-Initiatives-Patient-AssessmentInstruments/MMS/downloads/MMSHospital-WideAllConditionReadmissionRate.pdf 
Hersh, L., Salzman, B., \& Snyderman, D. (2015, July 15). Health Literacy in Primary Care Practice. Retrieved from https://www.aafp.org/afp/2015/0715/p118.html 
APPENDIX G

FOCUS GROUP INTERVIEW QUESTIONS 
From the data collected, infection has been noted as the most frequent diagnosis upon readmission of abdominal surgeries. This focus group is to brainstorm reasons you believe causes infection in the postabdominal surgeries.

Questions:

a. In your opinion what are the causes of postsurgical infection?

b. Why do you believe these are the causes of postsurgical infections?

c. Are there any other causes and categories that we did not discuss?

d. What can we do to prevent the occurrence of infection in our facilities? 
APPENDIX H

DATA EXTRACTION TOOL 
Table 1.

\section{DATA EXTRACTION TOOL}

\begin{tabular}{|c|c|c|c|c|c|c|c|c|c|c|c|c|c|c|}
\hline \multicolumn{15}{|c|}{ Data Extraction Tool } \\
\hline \multicolumn{10}{|c|}{ Patient Data } & \multicolumn{5}{|c|}{ Reason for Return } \\
\hline $\begin{array}{l}\text { Patient } \\
\text { Code }\end{array}$ & Age & Sex & $\begin{array}{l}\text { Marital } \\
\text { Status }\end{array}$ & $\begin{array}{l}\text { Length } \\
\text { of Stay } \\
\text { (LOS) }\end{array}$ & DRG's & Type of Surgery & $\begin{array}{l}\text { Date of } \\
\text { Surgery }\end{array}$ & $\begin{array}{l}\text { Number } \\
\text { of days } \\
\text { out before } \\
\text { return }\end{array}$ & $\begin{array}{l}\text { Diagnosis on } \\
\text { Return }\end{array}$ & $\begin{array}{l}\text { Un- } \\
\text { planned }\end{array}$ & Planned & DVT & Dehydration & Infection \\
\hline $01 \mathrm{~A}$ & $60-70$ & 1 & 1 & 5 & 330 & $\begin{array}{l}\text { Low anterior } \\
\text { resection with } \\
\text { diverting } \\
\text { colostomy }\end{array}$ & $12 / 19 / 26$ & 29 & Nausea vomiting & 1 & 0 & 0 & 1 & 0 \\
\hline $02 \mathrm{~A}$ & $60-70$ & 0 & 0 & 2 & 330 & $\begin{array}{l}\text { Robotic assist } \\
\text { right colon } \\
\text { resection }\end{array}$ & $7 / 672016$ & 3 & Abdominal pain & 1 & 0 & 0 & 0 & 0 \\
\hline 03A & Over 70 & 0 & 0 & 14 & 330 & $\begin{array}{l}\text { Abdominal } \\
\text { resection }\end{array}$ & $6 / 4 / 2016$ & 14 & Abdominal pain & 1 & 0 & 0 & 0 & 0 \\
\hline 04A & $60-70$ & 0 & 2 & 3 & 334 & $\begin{array}{l}\text { Small bowel } \\
\text { enteroscopy }\end{array}$ & $5 / 17 / 2016$ & 14 & $\begin{array}{l}\text { GI bleed/acute } \\
\text { blood loss }\end{array}$ & 1 & 0 & 0 & 0 & 0 \\
\hline $05 \mathrm{~A}$ & $60-70$ & 0 & 2 & 4 & 331 & $\begin{array}{l}\text { Colostomy } \\
\text { reversal }\end{array}$ & $4 / 28 / 2017$ & 10 & Fever, leukocytes & 1 & 0 & 0 & 0 & 1 \\
\hline 06A & $60-70$ & 1 & 2 & 10 & 329 & Right colectomy & $1 / 30 / 2017$ & 22 & $\begin{array}{l}\text { Small bowel } \\
\text { obstruction } \\
\text { (Exploratory lap). }\end{array}$ & 1 & 0 & 0 & 0 & 0 \\
\hline 07A & $\begin{array}{l}\text { Below } \\
60\end{array}$ & 1 & 2 & 15 & 330 & $\begin{array}{l}\text { Exploratory lap } \\
\text { lysis of adhesions. } \\
1 / 10 / 2017\end{array}$ & $1 / 10 / 2017$ & 16 & $\begin{array}{l}\text { Small Bowel } \\
\text { Obstruction with } \\
\text { lysis of adhesions }\end{array}$ & 1 & 0 & 0 & 0 & 0 \\
\hline $08 \mathrm{~A}$ & Over 70 & 1 & 0 & 6 & 329 & $\begin{array}{l}\text { Exploratory lap. } \\
\text { Cholecystectomy, } \\
\text { repair of colon }\end{array}$ & $12 / 27 / 2017$ & 22 & Fever & 1 & 0 & 0 & 0 & 1 \\
\hline 09A & $\begin{array}{l}\text { Below } \\
60\end{array}$ & 1 & 0 & 3 & 330 & $\begin{array}{l}\text { Robotic assist } \\
\text { laparoscopy }\end{array}$ & 7/12/2017 & 5 & Anastomic leak & 1 & 0 & 0 & 0 & 1 \\
\hline $10 \mathrm{~A}$ & Over 70 & 0 & 0 & 12 & 330 & Hemicolectomy & 6/14/2017 & 14 & $\begin{array}{l}\text { Drainage from } \\
\text { wound }\end{array}$ & 1 & 0 & 0 & 0 & 1 \\
\hline $11 \mathrm{~A}$ & $60-70$ & 0 & 0 & 4 & 330 & Right colectomy & $6 / 7 / 2017$ & 7 & $\begin{array}{l}\text { Wound } \\
\text { dehiscence }\end{array}$ & 1 & 0 & 0 & 0 & 1 \\
\hline
\end{tabular}




\begin{tabular}{|c|c|c|c|c|c|c|c|c|c|c|c|c|c|c|}
\hline $12 \mathrm{~A}$ & Over 70 & 1 & 3 & 14 & 329 & $\begin{array}{l}\text { Exploratory } \\
\text { laparotomy }\end{array}$ & $5 / 16 / 2017$ & 28 & Fall & 1 & 0 & 0 & 0 & 0 \\
\hline $13 \mathrm{~A}$ & Over 70 & 1 & 3 & 5 & 330 & $\begin{array}{l}\text { Robotic assist } \\
\text { sigmoid } \\
\text { colectomy } \\
\text { takedown fistula, } \\
\text { lysis of adhesions }\end{array}$ & $5 / 10 / 2017$ & 18 & $\begin{array}{l}\text { Vaginal and } \\
\text { rectal bleeding - } \\
\text { coagulopathy }\end{array}$ & 1 & 0 & 0 & 0 & 0 \\
\hline $14 \mathrm{~A}$ & Over 70 & 1 & 2 & 5 & 330 & $\begin{array}{l}\text { Low anterior } \\
\text { resection with } \\
\text { mesh }\end{array}$ & $\begin{array}{l}5 / 2 / \\
2017\end{array}$ & 29 & Pelvic abscess & 1 & 0 & 0 & 0 & 1 \\
\hline $15 \mathrm{~A}$ & $\begin{array}{l}\text { Below } \\
60\end{array}$ & 0 & 2 & 5 & 331 & $\begin{array}{l}\text { Robotic assist } \\
\text { laparotomy total } \\
\text { mesorectal } \\
\text { excision with loop } \\
\text { ileostomy }\end{array}$ & $4 / 27 / 2017$ & 18 & $\begin{array}{l}\text { Pelvic abscess } \\
\text { and pain }\end{array}$ & 1 & 0 & 0 & 0 & 1 \\
\hline $16 \mathrm{~A}$ & Over 70 & 1 & 2 & 14 & 329 & Hemicolectomy & $4 / 21 / 2017$ & 20 & $\begin{array}{l}\text { Urine retention } \\
\text { aspiration } \\
\text { pneumonia }\end{array}$ & 1 & 0 & 0 & 0 & 1 \\
\hline $17 \mathrm{~A}$ & Over 70 & 0 & 0 & 5 & 330 & $\begin{array}{l}\text { Extensive robotic } \\
\text { assist with } \\
\text { laparotomy with } \\
\text { lysis of adhesions }\end{array}$ & $4 / 13 / 2017$ & 7 & $\begin{array}{l}\text { Drainage from } \\
\text { wound }\end{array}$ & 1 & 0 & 0 & 0 & 1 \\
\hline $18 \mathrm{~A}$ & Over 70 & 1 & 0 & 12 & 330 & $\begin{array}{l}\text { Extended } \\
\text { hemicolectomy }\end{array}$ & $2 / 14 / 2017$ & 17 & Hyperkalemia & 1 & 0 & 0 & 0 & 0 \\
\hline $19 \mathrm{~A}$ & Over 70 & 1 & 3 & 15 & 330 & $\begin{array}{l}\text { Robotic assist } \\
\text { laparotomy, } \\
\text { sigmoid } \\
\text { colectomy, lysis of } \\
\text { adhesions } \\
\end{array}$ & $3 / 15 / 2017$ & 19 & $\begin{array}{l}\text { Cerebrovascular } \\
\text { Accident (CVA)- } \\
\text { stroke }\end{array}$ & 1 & 0 & 0 & 0 & 0 \\
\hline $20 \mathrm{~A}$ & Over 70 & 1 & 0 & 6 & 330 & $\begin{array}{l}\text { Right } \\
\text { hemicolectomy }\end{array}$ & $12 / 28 / 2016$ & 9 & $\begin{array}{l}\text { Difficulty in } \\
\text { breathing } \\
\text { /Respiratory } \\
\text { Infection } \\
\end{array}$ & 1 & 0 & 0 & 0 & 1 \\
\hline $21 \mathrm{~A}$ & Over 70 & 0 & 1 & 7 & 329 & $\begin{array}{l}\text { Exploratory } \\
\text { laparotomy. Right } \\
\text { colectomy }\end{array}$ & $11 / 10 / 2016$ & 3 & $\begin{array}{l}\text { Small Bowel } \\
\text { Obstruction }\end{array}$ & 1 & 0 & 0 & 0 & 0 \\
\hline $22 \mathrm{~A}$ & $\begin{array}{l}\text { Below } \\
60\end{array}$ & 0 & 0 & 7 & 330 & $\begin{array}{l}\text { Anastomic } \\
\text { stricture } \\
\text { colorectal region } \\
\text { with ileostomy }\end{array}$ & $10 / 13 / 2016$ & 14 & $\begin{array}{l}\text { lleostomy } \\
\text { reversal post } \\
\text { anastomic } \\
\text { stricture } \\
\text { colorectal region }\end{array}$ & 1 & 1 & 0 & 0 & 0 \\
\hline $23 \mathrm{~A}$ & $\begin{array}{l}\text { Below } \\
60\end{array}$ & 0 & 0 & 2 & 331 & Hemicolectomy & $9 / 01 / 2016$ & 10 & $\begin{array}{l}\text { Wound } \\
\text { dehiscence }\end{array}$ & 1 & 0 & 0 & 0 & 1 \\
\hline
\end{tabular}




\begin{tabular}{|c|c|c|c|c|c|c|c|c|c|c|c|c|c|c|}
\hline $24 \mathrm{~A}$ & $60-70$ & 1 & 2 & 14 & 329 & $\begin{array}{l}\text { Cystoscopy with } \\
\text { stents }\end{array}$ & $7 / 26 / 2016$ & 7 & $\begin{array}{l}\text { Colovesicular } \\
\text { fistula }\end{array}$ & 1 & 0 & 0 & 0 & 0 \\
\hline $25 \mathrm{~A}$ & $\begin{array}{l}\text { Below } \\
60\end{array}$ & 1 & 2 & 3 & 333 & $\begin{array}{l}\text { Colostomy } \\
\text { reversal }\end{array}$ & $5 / 10 / 2017$ & 25 & Gastric perfusion & 1 & 0 & 0 & 0 & 1 \\
\hline $26 \mathrm{~A}$ & $\begin{array}{l}\text { Below } \\
60\end{array}$ & 0 & 2 & 1 & 331 & Colon resection & $4 / 26 / 2017$ & 3 & Fecal peritonitis & 1 & 0 & 0 & 0 & 1 \\
\hline $27 \mathrm{~A}$ & $60-70$ & 1 & 2 & 13 & 329 & $\begin{array}{l}\text { Exploratory } \\
\text { Laparotomy. } \\
\text { Partial colectomy }\end{array}$ & $2 / 26 / 2017$ & 13 & $\begin{array}{l}\text { Inpatient } \\
\text { Rehabilitation }\end{array}$ & 1 & 0 & 0 & 0 & 0 \\
\hline $28 \mathrm{~A}$ & $60-70$ & 0 & 2 & 3 & 330 & $\begin{array}{l}\text { Primary repair of } \\
\text { massive inguinal } \\
\text { incarcerated } \\
\text { hernia repair and } \\
\text { sigmoid } \\
\text { colostomy }\end{array}$ & $2 / 16 / 2017$ & 12 & $\begin{array}{l}\text { Bowel } \\
\text { obstruction, } \\
\text { ischemic colon }\end{array}$ & 1 & 0 & 0 & 0 & 1 \\
\hline $29 \mathrm{~A}$ & $\begin{array}{l}\text { Above } \\
70\left(^{*}\right)\end{array}$ & 1 & 3 & 4 & 330 & Total colectomy & $1 / 12 / 2017$ & 18 & $\begin{array}{l}\text { Altered mental } \\
\text { status, } \\
\text { hypotension }\end{array}$ & 1 & 0 & 0 & 1 & 0 \\
\hline $30 \mathrm{~A}$ & $\begin{array}{l}\text { Below } \\
60\end{array}$ & 0 & 2 & 4 & 330 & $\begin{array}{l}\text { Robotic assist } \\
\text { laparotomy } \\
\text { sigmoid low } \\
\text { anterior resection }\end{array}$ & $5 / 25 / 2017$ & 10 & $\begin{array}{l}\text { Adenocarcinoma } \\
\text { of the colon } \\
\text { metastic to the } \\
\text { liver }\end{array}$ & 1 & 0 & 0 & 0 & 0 \\
\hline
\end{tabular}


Keys

\begin{tabular}{|c|c|}
\hline \multicolumn{2}{|c|}{ key } \\
\hline \multirow[t]{2}{*}{ Sex } & $1=F$ \\
\hline & $\mathbf{0}=\mathbf{M}$ \\
\hline \multirow[t]{4}{*}{ Marital Status } & 0=Married \\
\hline & 1=Divorced \\
\hline & 2=Single \\
\hline & 3=Widowed \\
\hline \multirow[t]{2}{*}{ Unplanned } & $1=$ Yes \\
\hline & $\mathbf{0}=$ No \\
\hline \multirow[t]{2}{*}{ Planned } & $1=$ Yes \\
\hline & 0=No \\
\hline \multirow{2}{*}{$\begin{array}{l}\text { Deep Vein } \\
\text { Thrombosis }\end{array}$} & 1=Yes \\
\hline & $0=$ No \\
\hline \multirow[t]{2}{*}{ Dehydration } & 1=Yes \\
\hline & 0=No \\
\hline \multirow[t]{2}{*}{ Infection } & $1=$ Yes \\
\hline & $\mathbf{0}=$ No \\
\hline Deceased & $*$ \\
\hline
\end{tabular}

\begin{tabular}{|l|l|}
\hline Key for Diagnosis Related Groups (DRGs) Represented in the Study \\
\hline DRG & Meaning of Code \\
\hline 329 & $\begin{array}{l}\text { Major small and large bowel procedures with major } \\
\text { complications }\end{array}$ \\
\hline 330 & Major small and large bowel procedures with complications \\
\hline 331 & $\begin{array}{l}\text { Major small and large bowel procedures without major } \\
\text { complications }\end{array}$ \\
\hline 333 & Rectal resection with complications or comorbidity \\
\hline 334 & Rectal resection without major complication or comorbidity \\
\hline
\end{tabular}


APPENDIX I

FISHBONE (ISHIKAWA) DIAGRAM 


\section{Diagram 1.1 FISHBONE (ISHIKAWA) DIAGRAM}

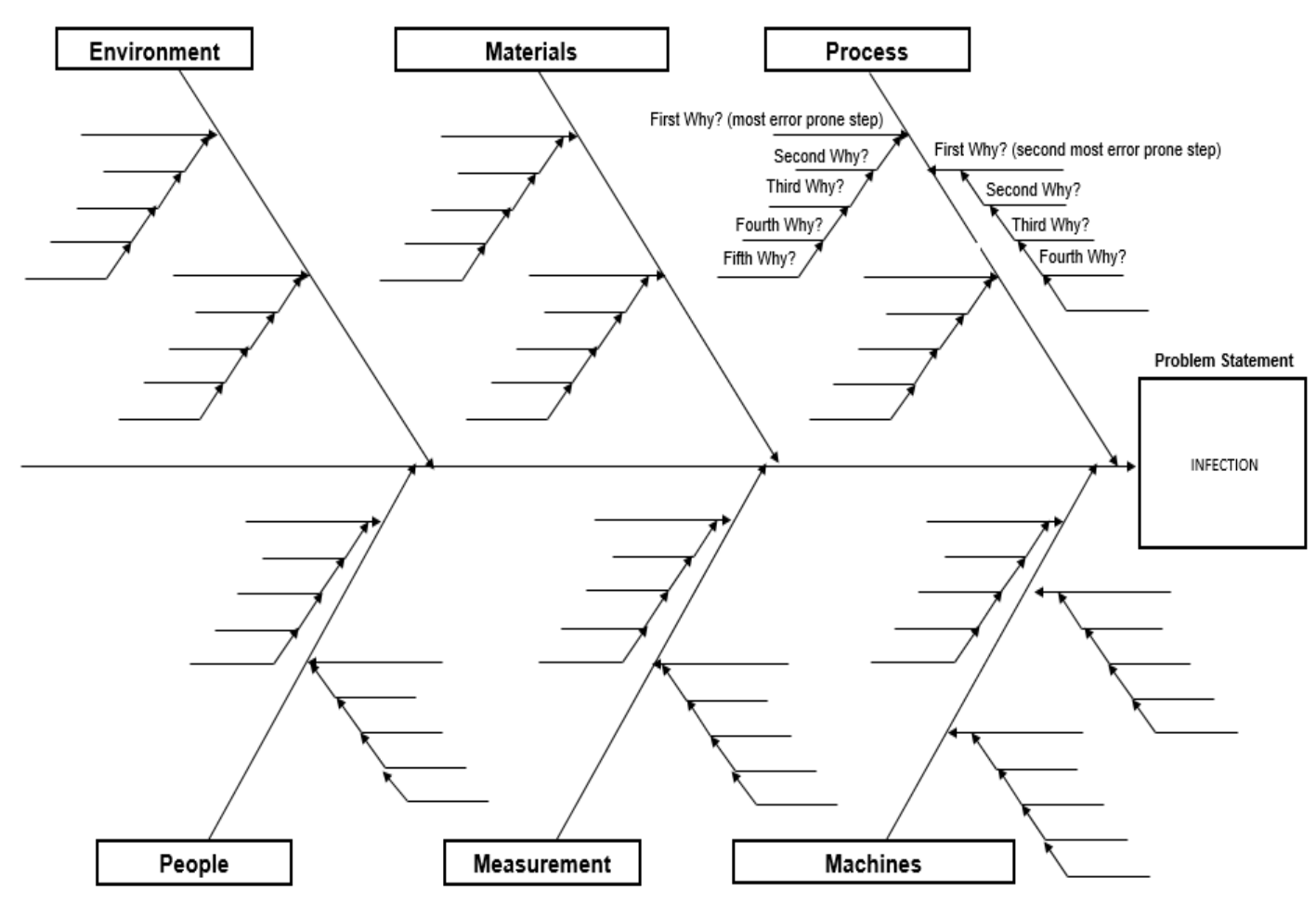


APPENDIX J

SURVEY 


\section{Survey of Stakeholder's Understanding of the Policy Developed}

Factors Contributing to 30-day Re-admission Rate in Postsurgical Patients at a Community Hospital: A re-evaluation of Hospital Policies and Proposal for Change.

\section{Survey}

The following statements relate to your belief about the overall policy development. For each statement rate your perceived satisfaction using five-point Likert Scale ranging from 5 (strongly agree), to 1(strongly disagree) to the extent you believe this project researcher was able to address key areas that may cause postsurgical infections in the policy created.

1. Overall, I would rate the clarity of the policy that was developed as:

$\begin{array}{ccccc}\text { Not clear } & \text { Fair } & \text { Unsure } & \text { Clear } & \text { Very Clear } \\ 1 & 2 & 3 & 4 & 5\end{array}$

2. Was the policy developed easy to understand?

$\begin{array}{ccccc}\text { Not easy to } & \text { Fair } & \text { Unsure } & \text { Easy to } & \text { Very easy to } \\ \text { Understand } & & & \text { Understand } & \text { Understand } \\ 1 & 2 & 3 & 4 & 5\end{array}$




\section{REFERENCE LIST}

Agency for Healthcare Research and Quality. (2013). Readmissions to US hospitals by procedure, 2010. Retrieved from https://www.hcupus.ahrq.gov/reports/statbriefs/sb154.pdf

Agency for Healthcare Research and Quality. (2014). Conditions with the largest number of adult hospital readmissions by payer, 2011. Retrieved from https://www.hcupus.ahrq.gov/reports/statbriefs/sb172-Conditions-Readmissions-Payer.pdf

Agency for Healthcare Research and Quality. (2018) Understanding quality measurement. Retrieved from https://www.ahrq.gov/professionals/quality-patientsafety/quality-resources/tools/chtoolbx/understand/index.html

Alnaif, M. (2015). The quality of healthcare. Retrieved from http://fac.ksu.edu.sa/sites/default/files/pa_505_5.pdf

American Association of Colleges of Nursing. (2006). The essentials of doctoral education for advanced nursing practice. Retrieved from http://www.aacn.nche.edu/DNP/pdf/Essentials.pdf

Ansari, S. F., Yan, H., Zou, J., Worth, R. M., \& Barbaro, N. M. (2018). Hospital length of stay and readmission rate for neurosurgical patients. Neurosurgery, 82(2), 173 181. doi:10.1093/neuros/nyx 160

Aquina, C. T., Becerra, A. Z., Probst, C. P., Xu, Z., Hensley, B. J., Iannuzzi, J. C., . . \& \& Fleming, F. J. (2016). Patients with adhesive small bowel obstruction should be primarily managed by a surgical ream. Annals of Surgery, 264(3), 437-447. doi:10.1097/sla.0000000000001861

Bartel, A., Chan, C., \& Kim, S. (2016). Should hospitals keep their patients longer? The role of inpatient care in reducing post-discharge. Retrieved from http://www.columbia.edu/ cc3179/medicare_2016.pdf

Bastable, S. B., Gramet, P., Jacobs, K., \& Sopczyk, D. L. (2011). Health professional as educator: Principles of teaching and learning. Sudbury, MA: Jones \& Bartlett Learning, LLC

Berry, J. G., Gay, J. C., Joynt Maddox, K., Coleman, E. A., Bucholz, E. M., O’Neill, M. R., . . \& \& Hall, M. (2018). Age trends in 30 day hospital readmissions: US national retrospective analysis. British Medical Journal Quality and Safety, 360. doi:10.1136/bmj.k497 
Carey, K. (2014). Measuring the hospital length of stay/readmission cost trade-off under a bundled payment mechanism. Health Economics, 24(7), 790-802.

doi:10.1002/hec.3061

Center for Medicaid and Medicare Services (2011). Hospital-wide (all-condition) 30-day risk-standardized readmission measure: Draft measure methodology report. Retrieved from https://www.cms.gov/Medicare/Quality-Initiatives-PatientAssessment-Instruments/MMS/downloads/MMSHospital-WideAllConditionReadmissionRate.pdf

Center for Medicaid and Medicare Services (2017). CMS manual system. Retrieved from https://www.cms.gov/Regulations-andGuidance/Guidance/Transmittals/2017Downloads/R234BP.pdf

Center for Medicaid and Medicare Services. (2018a). Hospital readmissions reduction program (HRRP). Retrieved from https://www.cms.gov/Medicare/QualityInitiatives-Patient-Assessment-Instruments/Value-BasedPrograms/HRRP/Hospital-Readmission-Reduction-Program.html

Center for Medicaid and Medicare Services (2018b). MS-DRG classification and software. Retrieved from https://www.cms.gov/Medicare/Medicare-Fee-forService-Payment/AcuteInpatientPPS/MS-DRG-Classifications-and-Software.html

Centers for Disease Control and Prevention. (2018). CDC policy process. Retrieved from https://www.cdc.gov/policy/analysis/process/index.html

Chen, L. (2013). A retrospective chart review of hospital-based wound discharge planning and 30-day readmission rates. Retrieved from https://search-proquestcom.ezproxy.andrews.edu/docview/1464392307? accountid=8313

Cheng, H., Chen, B. P-H., Soleas, I. M., Ferko, N. C., Cameron, C. G., \& Hinoul, P. (2017). Prolonged operative duration increases risk of surgical site infections: A systematic review. Surgical Infections, 18(6), 722-735. http://doi.org/10.1089/sur.2017.089

Chism, L. (2016). The doctor of nursing practice: A guide for the role development and professional issues ( $3^{\text {rd }}$ ed.). Burlington, MA: Jones \& Bartlett Learning.

Christensen, M., Welch, A., \& Barr, J. (2017). Husserlian descriptive phenomenology: A review of intentionality, reduction, and the natural attitude. Journal of Nursing Education and Practice, 7(8), 113. doi:10.5430/jnep.v7n8p113

Clarke, H., Poon, M., Weinrib, A., Katznelson, R., Wentlandt, K., \& Katz, J. (2015). Preventive analgesia and novel strategies for the prevention of chronic postsurgical pain. Drugs, 75(4), 339-351. doi:10.1007/s40265-015-0365-2

Clemson University. (2018). Focus groups. Retrieved from https://www.clemson.edu/assessment/surveys/focus-groups.html 
Conner, B., \& Johnson, E. (2017). Descriptive statistics: Use these tools to analyze data vital to practice-improvement projects. American Nurse Today, 12(11), 52-55.

Dadosky, A., Overbeck, H., Egnaczyk, G., Menon, S., Obrien, T., \& Chung, E. (2016). The effect of enhanced patient education on 30-day heart failure readmission rates. Heart \& Lung: The Journal of Acute and Critical Care, 45(4), 372. doi:10.1016/j.hrtlng.2016.05.002

Dearholt, S., Dang, D., \& Sigma Theta Tau International. (2012). Johns Hopkins nursing evidence-based practice: Models and guidelines. Retrieved from https://www.hopkinsmedicine.org/evidence-based-practice/ijhn_2017_ebp.html

Demidova-Rice, T. N., Hamblin, M. R., \& Herman, I. M. (2012). Acute and impaired wound healing: Pathophysiology and current methods for drug delivery, part 1: Normal and chronic wounds: Biology, causes, and approaches to care. Advance Skin Wound Care, 25(7), 304-314. doi: 10.1097/01.ASW.0000416006. 55218.d0

Donzé, J., Lipsitz, S., Bates, D. W., \& Schnipper, J. L. (2013). Causes and patterns of readmissions in patients with common comorbidities: Retrospective cohort study. British Medical Journal, 347. doi:10.1136/bmj. 77171

Essential Evidence Plus. (2018). Level of evidence. Retrieved from http://www.essentialevidenceplus.com/product/ebm_loe.cfm?show=oxford

Fitzpatrick J. J., \& Whall A. L. (2005). Conceptual models of nursing, analysis, and application (4th ed.). Upper Saddle River, NJ: Pearson Prentice-Hall.

Florida State University College of Medicine. (2016). Evidence-based medicine tutorial. Retrieved from http://med.fsu.edu/index.cfm?page=medicalinformatics.ebmTutorial

Francis, L., \& Fitzpatrick, J. J. (2013). Postoperative pain: Nurses' knowledge and patients' experiences. Pain Management Nursing, 14(4), 351-357. doi: 10.1016/j.pmn.2012.05.002

George, J. B. (2011). Nursing theories: The base for professional nursing practice. Upper Saddle River, NJ: Pearson Education.

Grice, E. A., \& Segre, J. A. (2011). The skin microbiome. Nature reviews. Microbiology, 9(4), 244-53.

Han, S., Smith, T. S., \& Gunnar, W. (2014). Descriptive analysis of 30-day readmission after inpatient surgery discharge in the Veterans Health Administration. Journal of the American Medical Association Surgery, 149(11), 1162-1168. doi:10.1001/jamasurg.2014.1706 
Hari, M., \& Rosenzweig, M. (2012). Incidence of preventable postoperative readmissions following pancreaticoduodenectomy: Implications for patient education. Oncology Nursing Forum, 39(4), 408-412. doi: 10.1188/12.onf.408412

Health Resource and Service Administration. (2011). Quality improvement. Retrieved from https://www.hrsa.gov/sites/default/files/quality/toolbox/pdfs/qualityimprovement. pdf

Hernandez-Boussard, T., Graham, L. A., Desai, K., Wahl, T. S., Aucoin, E., Richman, J. S., . . \& Hawn, M. T. (2017). The fifth vital sign. Annals of Surgery, 266(3), 516-524. doi:10.1097/sla.0000000000002372

Hersh, A. M., Masoudi, F. A., \& Allen, L. A. (2013). Post-discharge environment following heart failure hospitalization: Expanding the view of hospital readmission. Journal of the American Heart Association: Cardiovascular and Cerebrovascular Disease, 2(2).

Hersh, L., Salzman, B., \& Snyderman, D. (2015). Health literacy in primary care practice. American Family Physician, 92(2), 118-24.

Huckfeldt, P. J., Mehrotra, A., \& Hussey, P. S. (2016). The relative importance of postacute care and readmissions for post-discharge spending. Health Services Research, 51(5), 1919-1938. doi:10.1111/1475-6773.12448

Huegel, L. (2014). Discharge/transitioning planning. Retrieved from http://info.lakelandregional.org/Policies/Care

Hume, K., \& Tomsik, E. (2014). Enhancing patient education and medication reconciliation strategies to reduce readmission rates. Hospital Pharmacy, 49(2), 112-114. http://doi.org/10.1310/hpj4902-112

Institute of Healthcare Improvement. (2018). The four phases of an improvement project. Retrieved from http://app.ihi.org/lmsspa/\#/6cb1c614-884b-43ef-9abdd90849f183d4/6d2b36c7-eee1-41b4-a852-67d1c4837404/lessonDetail/176bda31d020-4189-b4eb-05033d6183bd/page/0

Jerónimo, R. A., Segura, J. M., \& Amorós, M. A. (2015). Dehydration in the hospitalized elderly. Nutricion Hospitalaria, 32(S2), 22. doi: 10.3305/nh.2015.32.sup2.10275

John Hopkins Medicine (2018). Surgical site infections. Retrieved from https://www.hopkinsmedicine.org/healthlibrary/conditions/surgical_care/surgical_ site_infections_134,144 
Journal of the American Medical Association Network. (2017). Hospital readmissions after surgery associated mostly with complications related to surgical procedure. Retrieved from http://media.jamanetwork.com/news-item/hospital-readmissionsafter-surgery-associated-mostly-with-complications-related-to-surgical-procedure/

Kariv, Y., Wang, W., Senagore, A. J., Hammel, J. P., Fazio, V. W., \& Delaney, C. P. (2006). Multivariable analysis of factors associated with hospital readmission after intestinal surgery. The American Journal of Surgery, 191, (3) 364-371, ISSN 0002-9610, http://dx.doi.org/10.1016/j.amjsurg.2005.10.038.

Kassin, M. T., Owen, R. M., Perez, S., Leeds, I., Cox, J. C., Schneider, K., ... \& Sweeney, J. F. (2012). Risk factors for 30-day hospital readmission among general surgery patients. Journal of the American College of Surgeons, 215(3), 322-330. http://doi.org/10.1016/j.jamcollsurg.2012.05.024

Köppen, P. J., Dorner, T. E., Stein, K. V., Simon, J., \& Crevenna, R. (2018). Health literacy, pain intensity and pain perception in patients with chronic pain. Wiener klinische Wochenschrift, 130(1), 23-30. doi:10.1007/s00508-017-1309-5

Kourkouta, L., \& Papathanasiou, I. V. (2014). Communication in nursing practice. Materia Socio-Medica, 26(1), 65-67. http://doi.org/10.5455/msm.2014.26.65-67

Kripalani, S., Theobald, C. N., Anctil, B., \& Vasilevskis, E. E. (2014). Reducing hospital readmission: Current strategies and future directions. Annual Review of Medicine, 65, 471-485.

Lagoe, R. J., Nanno, D. S., \& Luziani, M. E. (2012). Quantitative tools for addressing hospital readmissions. BioMed Central Research Notes, 5(1), 620. doi:10.1186/1756-0500-5-620

Leach, B., Morgan, P., de Oliveira, J. S., Hull, S., Østbye, T., \& Everett, C. (2017). Primary care multidisciplinary teams in practice: A qualitative study. BioMed Central Family Practice, 181-10. doi:10.1186/s12875-017-0701-6

Leppin, A. L., Gionfriddo, M. R., Kessler, M., Brito, J. P., Mair, F. S., Gallacher, K., ... \& Montori, V. M. (2014). Preventing 30-day hospital readmissions: A systematic review and meta-analysis of randomized trials. Journal of the American Medical Association Internal Medicine, 174(7), 1095-107.

Leviste Buban-Aseron, M. (2010). Strengths and limitations of Orem's theory. Retrieved from http://upoun207tfn.blogspot.com/2010/07/strengths-and-limitations-oforems.html

Literacy Project Foundation (2015). Statistics. Retrieved from https://declara.com/collection/9b4e3853-c5be-42c0-9ac07e23d6c2bc06/post/8f4629ab-8a68-438e-a3bb-ec2ee39397ba 
Lu, M. L. R., Davila, C. D., Shah, M., Wheeler, D. S., Ziccardi, M. R., Banerji, S., \& Figueredo, V. M. (2016). Marital status and living condition as predictors of mortality and readmissions among African Americans with heart failure. International Journal of Cardiology, 222, 313-318. doi: 10.1016/j.ijcard.2016.07.185

Ma, C., McHugh, M. D., \& Aiken, L. H. (2015). Organization of hospital nursing and 30day readmissions in medicare patients undergoing surgery. Medical Care, 53(1), 65-70. http://doi.org/10.1097/MLR.0000000000000258

Mahmoud, A. N., \& Elgendy, I. Y. (2018). Gender impact on 30-day readmissions after hospitalization with acute myocardial infarction complicated by cardiogenic shock (from the 2013 to 2014 national readmissions database). The American Journal of Cardiology, 121(5), 523-528. doi: https://doi.org/10.1016/j.amjcard.2017.11.023

Mayo Clinic. (2018). Readmission rates. Retrieved from https://www.mayoclinic.org/about-mayo-clinic/quality/qualitymeasures/readmission-rates

Mccormack, R., Michels, R., Ramos, N., Hutzler, L., Slover, J. D., \& Bosco, J. A. (2013). Thirty-day readmission rates as a measure of quality: Causes of readmission after orthopedic surgeries and accuracy of administrative data. Journal of Healthcare Management, 58(1), 64-76.

Mittler, J. N., O’Hora, J. L., Harvey, J. B., Press, M. J., Volpp, K. G., \& Scanlon, D. P. (2013). Turning readmission reduction policies into results: Some lessons from a multistate initiative to reduce readmissions. Population Health Management, 16(4), 255-260. http://doi.org/10.1089/pop.2012.0087

Moore, C. D., Gao, K., \& Shulan, M. (2013). Racial, income, and marital status disparities in hospital readmissions within a veterans-integrated health care network. Evaluation \& The Health Professions, 38(4), 491-507. doi:10.1177/0163278713492982

Moran, K., Burson, R., \& Conrad, D. (2017). The doctor of nursing practice scholarly project: A framework for success (2nd ed.). Boston: MA. Jones \& Bartlett Learning.

Morris, D., Rohrbach, J., Rogers, M., Mary, L., Sundaram, T., Sonnad, S., ... \& Sims, C. (2011). The surgical revolving door: Risk factors for hospital readmission, Journal of Surgical Research, 170, (2), ISSN 0022-4804, https://doi.org/10.1016/j.jss.2011.04.049.

Napolitano, F., Tomassoni, D., Cascone, D., Giuseppe, G. D., Mauro, M. D., \& Rago, V. (2018). Evaluation of hospital readmissions for surgical site infections in Italy. European Journal of Public Health, 28(3), 421-425. doi:10.1093/eurpub/ckx205 
Neuman, M. D., \& Werner, R. M. (2016). Marital status and postoperative functional recovery. Journal of the American Medical Association Surgery, 151(2), 194. doi:10.1001/jamasurg.2015.3240

Nursing Theories. (2011). Dorothea Orem's self-care theory. Retrieved from http://currentnursing.com/nursing_theory/self_care_deficit_theory.html

O'Brien, C., Valsdottir, L., Wasfy, J. H., Strom, J. B., Secemsky, E. A., Wang, Y., \& Yeh, R. W. (2017). Comparison of 30-day readmission rates after hospitalization for acute myocardial infarction in men versus women. The American Journal of Cardiology, 120(7), 1070-1076. doi: https://doi.org/10.1016/j.amjcard.2017.06.046

Ohnuma, T., Shinjo, D., Brookhart, A. M., \& Fushimi, K. (2018). Predictors associated with unplanned hospital readmission of medical and surgical intensive care unit survivors within 30 days of discharge. Journal of Intensive Care, 6(1), 14. doi:10.1186/s40560-018-0284-x

Oregon Health and Science University. (2017). Evidence-based practice toolkit for nursing. Retrieved from http://libguides.ohsu.edu/ebptoolkit

Orem, D. E. (1995). Nursing concepts of practice (5th ed.). St. Louis, MO: Mosby-Year Book.

Oxford Centre for Evidence-based Medicine (2011). Levels of evidence. Retrieved from https://www.cebm.net/wp-content/uploads/2014/06/CEBM-Levels-of-Evidence2.1.pdf

Polit, D. F., \& Beck, C. T. (2008). Nursing research: Generating and assessing evidence for nursing practice. Philadelphia, PA: Wolters Kluwer Health

Reinberg, S. (2015). Infection likely cause of post-surgery readmission. Retrieved from https://www.webmd.com/women/news/20150203/infection-most-likely-cause-ofhospital-readmission-after-surgery\#1

Sarin, A., Litonius, E. S., Naidu, R., Yost, C. S., Varma, M. G., \& Lee-Lynn, C. (2016). Successful implementation of an enhanced recovery after surgery program shortens length of stay and improves postoperative pain, and bowel and bladder function after colorectal surgery. BioMed Central Anesthesiology, 16(1). doi:10.1186/s12871-016-0223-0

Serra-Majem, L. (2015). Opening remarks: The burden of disease attributable to hydration in Europe. Nutricion Hospitalaria, 32(S2), 3. doi:10.3305/nh.2015.32.sup2.10260

Social Research Methods. (2006). Descriptive statistics. Retrieved from https://www.socialresearchmethods.net/kb/statdesc.htm. 
Statistical Solutions. (2017). SPSS statistics help. Retrieved from http://www.statisticssolutions.com/spss-statistics-help/

Sullivan, L. M. (2014). Essentials of biostatistics in public health. Burlington, MA: Jones $\&$ Bartlett Learning

Sutherland, T., David-Kasdan, J. A., Beloff, J., Mueller, A., Whang, E. E., Bleday, R., \& Urman, R. D. (2016). Patient and provider-identified factors contributing to surgical readmission after colorectal surgery. Journal of Investigative Surgery, 29(4), 195-201. doi:10.3109/08941939.2015.1124947

University of California, Santa Barbara. (2016). Creation, review, and approval process. Retrieved from http://www.policy.ucsb.edu/policies/creation-review-approvalprocess

University of Washington. (2018). Evidence-based practice tools. Retrieved from http://guides.lib.uw.edu/friendly.php?s=hsl/ebptools

Vassar, M., \& Holzmann, M. (2013). The retrospective chart review: Important methodological considerations. Journal of Educational Evaluation for Health Professions, 10, 12. http://doi.org/10.3352/jeehp.2013.10.12

Yazdanian, F., Azarfarin, R., Aghdaii, N., Jalali Motlagh, S., Faritous, Z., Alavi, M., \& Hosseini, S. (2012). Relationship between gender and in-hospital morbidity and mortality after coronary artery bypass grafting surgery in an Iranian population. Research in Cardiovascular Medicine, 1(1), 17-22. http://doi.org/10.5812/cardiovascmed.4543

Zaccagnini M. E., \& White, K. W. (2014). Healthcare: Policy for advocacy in healthcare. The doctor of nursing practice essentials: A new model for advanced practice nursing ( $2^{\text {nd }}$ ed.) Burlington, MA: Jones \& Bartlett Learning. 